\title{
On Industry Structure and Firm Conduct in Long Run Equilibrium
}

\author{
Prof. Jean-Paul Chavas \\ Department of Agricultural and Applied Economics \\ Taylor Hall, University of Wisconsin, Madison, WI 53706 \\ Tel: +1-608-261-1944Ｅ-mail: jchavas@wisc.edu
}

Received: September 16, $2010 \quad$ Accepted: September 29, $2010 \quad$ doi:10.5430/jms.v1n1p2

This research was supported by a USDA grant to the Food System Research Group, University of Wisconsin, Madison.

\begin{abstract}
:
This paper presents an analysis of long run equilibrium of industry structure and firm conduct allowing for entry and exit, and cost heterogeneity among firms. It investigates the case of firms' conduct/markups that emerges as the stationary equilibrium from long run evolutionary selection over time. Treating the number of firms as endogenous provides linkages between firms' conduct and market structure. The implications of cost structure for market equilibrium price, firms' conduct and industry concentration are investigated. The effects of fixed cost and entry/exit on long run industry equilibrium are examined. The analysis shows how globalization can help reduce the firms' exercise of market power, increase the responsiveness of aggregate supply, and reduce price sensitivity to shocks. It also shows how neglecting either entry/exit or adjustments in firm conduct underestimates the aggregate effects of globalization.
\end{abstract}

Keywords: Entry/exit, Long run equilibrium, Heterogeneous firms, Oligopoly.

\section{Introduction}

The trend toward globalized markets has stimulated much research on its economic implications. Globalization is expected to have two effects on efficiency. First, expanding the scope of a market can force the least productive firms to exit and replace them by more productive firms, thus leading to efficiency gains (e.g., Melitz). These productivity gains are been found to be large (e.g., Pavcnik). The importance of these selectivity effects has stressed the role of entry/exit decisions among heterogeneous firms in industry equilibrium (e.g., Ericson and Pakes; Melitz and Ottaviano). Second, globalization can be associated with increased competition. The entry of new firms in an industry can contribute to reducing the exercise of market power and generate additional "pro-competitive" efficiency gains. The role of imperfect competition has been analyzed extensively in previous research (e.g., Scherer; Tirole; Friedman and Mezzetti). (Note 1) But these two effects are not independent: the entry of new firms can generate both productivity gains and a reduction in oligopoly rents. Yet, these two effects have often been examined separately. For example, Melitz, Melitz and Ottaviano, Arkolakis et al., and Feenstra all examine the effects of globalization under entry/exit, but they restrict their analysis to monopolistic competition. This neglects possible pro-competitive effects of globalization. Alternatively, the effects of market power have been examined by Dixon and Somma, and Muller and Normann for duopoly, and by Dixit (1986) and Friedman and Mezzetti for oligopoly. But these studies took the number of firms as given. By assuming an exogenous industry structure, they do not capture "pro-competitive" effects. When globalization is associated with increased competition, these pro-competitive effects take the form of changing pricing rules that evolve from imperfectly-competitive pricing (typically in the form of "high markups") toward competitive pricing (where marginal cost pricing applies). This suggests the need to investigate these two effects jointly. In other words, there is a need to examine the joint determination of industry structure and pricing rules under entry/exit among heterogeneous firms. This is the main objective of this paper. Below, we associate the choice of pricing rules (markups) with firm conduct. And we focus our attention on long run industry equilibrium.

This paper investigates the long run equilibrium of firms in a single-product industry, treating firm conduct/markups as endogenous and allowing entry/exit of heterogeneous firms. We analyze long run behavior as the stationary outcome from evolutionary dynamics. (Note 2) We consider the case of heterogeneous firms that learn from experimenting with their own conduct and its effect on firm profit. In this context, allowing for entry/exit, long run firms' conduct and industry equilibrium arise from evolutionary selection over time. Allowing for entry/exit in the industry, we treat the industry structure as endogenous. (Note 3) This allows various market structures as well as firm conducts to arise, going 
from monopoly to oligopoly to competitive markets. This provides useful information on the determinants of both firms' conduct and industry structure in long run equilibrium.

The analysis allows for non-constant marginal cost and firm heterogeneity involving both fixed cost and variable cost. The cost heterogeneity across firms can come from two sources: different production technology, and/or different access to market. The first source means that some firms have access to improved technology that reduces their cost of production and gives them some comparative advantage. The second source means that transaction costs vary across firms. This can be due to location differences (e.g., different transportation cost), differential access to market information, and/or different trade policy impacts (e.g., with quotas, taxes or tariffs/subsidies that vary across firms). The effects of changing transaction costs are relevant in the context of studying the globalization of markets. Indeed, transaction costs reduce incentives to produce and trade. By reducing the number of market participants, they can contribute to the creation of "local markets" that fail to be integrated in a global economy. In this context, the development of global markets is supported by a reduction of transaction costs associated with lower transportation and information costs, and by a move toward market liberalization policies. Our analysis provides useful information on how cost structures can affect pricing and industry behavior in global markets. Finally, while there is some anecdotal evidence that price instability may increase in thin and concentrated markets, it remains unclear when such relationships may develop. The paper examines how market concentration can affect supply responsiveness and price sensitivity.

This paper makes several contributions. First, it refines the role played by both fixed cost and non-constant marginal cost in the long run equilibrium of heterogeneous firms under entry/exit. Second, the paper investigates the determinants of firms' conduct/markup in long run equilibrium. It analyses how the linkages between firms' conduct (representing the exercise of market power) and market structures (represented by the number of active firms) are affected by cost structures and market conditions. In particular, it examines how Bertrand/competitive pricing can emerge through evolutionary selection over time even when the number of active firms remains relatively small. Third, analyzing the interactions between entry/exit and firm conduct in long run equilibrium provides useful information on the economics of globalization. It shows how globalization can help reduce the firms' exercise of market power, increase the responsiveness of aggregate supply, and reduce price sensitivity to shocks. It also shows how neglecting either entry/exit or adjustments in firm conduct underestimates the aggregate effects of globalization. This stresses that a search for larger gains from globalization should include the joint determination of entry/exit and firm conduct/markups.

The paper is organized as follows. Section 2 presents the model. Section 3 analyzes the long run market equilibrium under entry/exit of heterogeneous firms, with implications for linkages between firms' conduct and market structure. Section 4 investigates the properties of steady state industry behavior when both the number of active firms and the exercise of market power are endogenous, with special attention given to the role of fixed cost. Section 5 discusses implications for the economics of globalization. Finally, section 6 presents concluding comments.

\section{The model}

Consider an industry composed of firms producing a homogenous product with an aggregate demand given by the price dependent demand $\mathrm{p}(\mathrm{Y})$, where $\mathrm{Y}$ denotes aggregate quantity consumed during a given time period. The quantity $\mathrm{Y}$ can be produced by a set $M$ of potential firms, $M=\{1, \ldots, m\}$. The i-th firm produces output $y_{i} \geq 0$ at $\operatorname{cost} C_{i}\left(y_{i}\right) \geq 0$. Our analysis focuses on the following specification. First, we assume that the demand function is linear:

$\mathrm{p}(\mathrm{Y})=\alpha_{1}-\alpha_{2} \mathrm{Y}$,

with $\alpha_{2}<0$. Second, we assume that the cost function of the i-th firm satisfies:

$\mathrm{C}_{\mathrm{i}}\left(\mathrm{y}_{\mathrm{i}}\right)=\mathrm{c}_{0 \mathrm{i}}+\mathrm{c}_{1 \mathrm{i}} \mathrm{y}_{\mathrm{i}}+1 / 2 \mathrm{c}_{2} \mathrm{y}_{\mathrm{i}}^{2}$, for $\mathrm{y}_{\mathrm{i}}>0$,

$$
=0, \text { for } \mathrm{y}_{\mathrm{i}}=0,
$$

where $c_{0 i} \geq 0$ denotes fixed cost, $c_{1 i}>0$ and $c_{2} \geq 0, i \in M$. Our analysis distinguishes between inactive firms (when $\left.y_{i}=0\right)$ and active firms (when $\mathrm{y}_{\mathrm{i}}>0$ ).

When $\mathrm{c}_{2}>0$, equation (2) allows for non-constant marginal cost. This relaxes the assumption of constant marginal cost that has sometimes been imposed in previous research (e.g., Melitz). From (2), the technology facing the i-th firm can exhibit increasing returns to scale (IRTS), constant returns to scale (CRTS), or decreasing returns to scale (DRTS) depending on whether $\mathrm{c}_{2}<2 \mathrm{c}_{0 \mathrm{i}} / \mathrm{y}_{\mathrm{i}}^{2}, \mathrm{c}_{2}=2 \mathrm{c}_{0 \mathrm{i}} / \mathrm{y}_{\mathrm{i}}^{2}$, or $\mathrm{c}_{2}>2 \mathrm{c}_{0 \mathrm{i}} / \mathrm{y}_{\mathrm{i}}^{2}$, respectively. This shows that the cost specification in (2) is flexible in its representation of returns to scale. For example, the technology of the i-th firm would exhibit global IRTS when fixed cost $\mathrm{c}_{0 \mathrm{i}}$ is positive and $\mathrm{c}_{2}=0$; it would exhibit global CRTS when $\mathrm{c}_{0 \mathrm{i}}=\mathrm{c}_{2}=0$; and it would exhibit 
global DRTS when $\mathrm{c}_{0 \mathrm{i}}=0$ and $\mathrm{c}_{2}>0$. Importantly, while $\mathrm{c}_{2}$ is treated as constant, firm heterogeneity is captured by the cost parameters $c_{0 i}$ and $c_{1 i}$. This allows for heterogeneity in both fixed cost $c_{0 \mathrm{i}}$ and variable cost (through $\mathrm{c}_{1 \mathrm{i}}$ ). And the heterogeneity in fixed $\operatorname{cost} \mathrm{c}_{0 \mathrm{i}}$ allows returns to scale to differ across firms. As the cost parameters $\left(\mathrm{c}_{0 \mathrm{i}}\right.$, $\left.\mathrm{c}_{1 \mathrm{i}}\right)$ vary among the $\mathrm{m}$ potential firms, we denote their distribution by the distribution function $\mathrm{F}\left(\tilde{\mathrm{c}}_{0}, \tilde{\mathrm{c}}_{1}\right)$.

Throughout, we assume that the market is large enough to sustain at least one active firm. Our analysis addresses the determination of firm conduct and industry structure allowing for entry/exit among heterogeneous firms. In this context, the specification given in (1)-(2) provides a reasonably flexible representation of both supply and demand conditions.

We want to allow a generic representation of firms' behavior. This can range from competition to oligopoly behavior, and to monopoly pricing. We start with the classical Lerner index representing pricing behavior. The Lerner index associated with the $\mathrm{i}$-th active firm (with output $\mathrm{y}_{\mathrm{i}}>0$ ) is

$\mathrm{L}_{\mathrm{i}} \equiv\left[\mathrm{p}(\mathrm{Y})-\partial \mathrm{C}_{\mathrm{i}}\left(\mathrm{y}_{\mathrm{i}}\right) / \partial \mathrm{y}_{\mathrm{i}}\right] / \mathrm{p}(\mathrm{Y})$,

$i \in$ M. Using competition as benchmark, the Lerner index $L_{i}$ in (3a) measures the relative price enhancement obtained due to the $\mathrm{i}$-th firm's exercise of market power. $\mathrm{L}_{\mathrm{i}}=0$ identifies a competitive firm where marginal cost pricing applies. $\mathrm{L}_{\mathrm{i}}>0$ occurs when the $\mathrm{i}$-th firm has market power as price exceeds its marginal cost. In general, a rise in $\mathrm{L}_{\mathrm{i}}$ is interpreted as an increase in the exercise of market power by the i-th firm. Equation (3a) defines the mark-up pricing implemented by the i-th firm, reflecting its conduct. Below, we will treat this conduct as endogenous and investigate its linkages with industry long run equilibrium. We will work with the closely related representation

$\mathrm{v}_{\mathrm{i}} \equiv \mathrm{L}_{\mathrm{i}} \varepsilon / \mathrm{s}_{\mathrm{i}}-1$,

where $\varepsilon \equiv-[\partial \operatorname{lnp}(\mathrm{Y}) / \partial \ln (\mathrm{Y})]-1>0$ is the price elasticity of demand, and $\mathrm{s}_{\mathrm{i}} \equiv \mathrm{y}_{\mathrm{i}} / \mathrm{Y}$ is the market share of the $\mathrm{i}$-th firm. It follows that competitive markets (where $\mathrm{L}_{\mathrm{i}}=0$ ) are associated with $\mathrm{v}_{\mathrm{i}}=-1$ for all active firms. Alternatively, under imperfect competition (where $\mathrm{L}_{\mathrm{i}}>0$ ), we have $\mathrm{v}_{\mathrm{i}}>-1$. Equation (3b) shows explicitly the role played by the price elasticity of demand $\varepsilon$ and the market share $\mathrm{s}_{\mathrm{i}}$. Given $\mathrm{L}_{\mathrm{i}} \equiv\left(1+\mathrm{v}_{\mathrm{i}}\right) \mathrm{s}_{\mathrm{i}} / \varepsilon$, an increase the Lerner index $\mathrm{L}_{\mathrm{i}}$ can be associated with a rise in the market share $\mathrm{s}_{\mathrm{i}}$, a rise in $\mathrm{v}_{\mathrm{i}}$, and/or a more inelastic demand (i.e., a decline in $\varepsilon$ ). In general, $\mathrm{v}_{\mathrm{i}}$ measures departures from marginal cost pricing for the $i$-th firm. As shown by Dixit (1986) and others, specific values of $v_{i}$ can capture firm conduct under alternative strategic games. This includes $v_{i}=-1$, which corresponds to Bertrand price competition where there is no anticipated price response to the $\mathrm{i}$-th firm supply. It also includes $\mathrm{v}_{\mathrm{i}}=0$, which corresponds to a Cournot quantity game where the i-th firm expects no quantity response from other firms to its own supply decision. Finally, it includes $v_{i}=\sum_{j \neq i} y_{j} / y_{i}$, which corresponds to market collusion where all firms behave as a cartel implementing monopoly pricing. This shows that $\mathrm{v}_{\mathrm{i}}$ in $(3 \mathrm{~b})$ provides a convenient representation of firms' conduct (e.g., Genesove and Mullin).

For the i-th active firm, combining (3a) and (3b) yields

$\mathrm{G}_{\mathrm{i}}\left(\mathrm{y}_{\mathrm{i}}, \mathrm{Y}, \mathrm{v}_{\mathrm{i}}\right) \equiv \mathrm{p}(\mathrm{Y})-\partial \mathrm{C}_{\mathrm{i}}\left(\mathrm{y}_{\mathrm{i}}\right) / \partial \mathrm{y}_{\mathrm{i}}+\mathrm{y}_{\mathrm{i}}\left(1+\mathrm{v}_{\mathrm{i}}\right)[\partial \mathrm{p}(\mathrm{Y}) / \partial \mathrm{Y}]=0$,

or, under the specification (1)-(2),

$\mathrm{G}_{\mathrm{i}}\left(\mathrm{y}_{\mathrm{i}}, \mathrm{Y}, \mathrm{v}_{\mathrm{i}}\right) \equiv \alpha_{1}-\alpha_{2} \mathrm{Y}-\mathrm{c}_{1 \mathrm{i}}-\mathrm{c}_{2} \mathrm{y}_{\mathrm{i}}-\alpha_{2} \mathrm{y}_{\mathrm{i}}\left(1+\mathrm{v}_{\mathrm{i}}\right)=0$.

We assume that $\left[c_{2}+\alpha_{2}\left(1+v_{i}\right)\right]>0$. (Note 4) It follows that $G_{i}\left(y_{i}, Y, v_{i}\right)$ is strictly decreasing in $y_{i}$. Then, solving equation (4b) for yi gives by $\mathrm{y}_{\mathrm{i}}^{\mathrm{a}}\left(\mathrm{Y}, \mathrm{v}_{\mathrm{i}}\right)=\left[\alpha_{1}-\alpha_{2} \mathrm{Y}-\mathrm{c}_{1 \mathrm{i}}\right] /\left[\mathrm{c}_{2}+\alpha_{2}\left(1+\mathrm{v}_{\mathrm{i}}\right)\right]$, with associated firm profit $\pi_{\mathrm{i}}^{\mathrm{a}}\left(\mathrm{Y}, \mathrm{v}_{\mathrm{i}}\right) \equiv \mathrm{p}(\mathrm{Y}) \mathrm{y}_{\mathrm{i}}^{\mathrm{a}}$ $-c_{0 i}-c_{1 i} y_{i}^{a}-1 / 2 c_{2}\left(y_{i}^{a}\right)^{2}=-c_{0 i}+\left[1 / 2 c_{2}+\alpha_{2}\left(1+v_{i}\right)\right]\left[\left(\alpha_{1}-\alpha_{2} Y-c_{1 i}\right) /\left(c_{2}+\alpha_{2}\left(1+v_{i}\right)\right]^{2}\right.$. Since no firm would produce under negative profit, it follows that $\pi_{\mathrm{i}}^{\mathrm{a}}\left(\mathrm{Y}, \mathrm{v}_{\mathrm{i}}\right) \geq 0$ for any active firm. Thus, given $\mathrm{Y}$ and $\mathrm{v}_{\mathrm{i}}$, the decision of the $\mathrm{i}$-th firm can be written as

$$
\mathrm{y}_{\mathrm{i}}^{+}\left(\mathrm{Y}, \mathrm{v}_{\mathrm{i}}\right)=\mathrm{y}_{\mathrm{i}}^{\mathrm{a}}\left(\mathrm{Y}, \mathrm{v}_{\mathrm{i}}\right) \text { if } \mathrm{y}_{\mathrm{i}}^{\mathrm{a}}\left(\mathrm{Y}, \mathrm{v}_{\mathrm{i}}\right)>0 \text { and } \pi_{\mathrm{i}}^{\mathrm{a}}\left(\mathrm{Y}, \mathrm{v}_{\mathrm{i}}\right) \geq 0 \text {, }
$$

$=0$ otherwise,

or, under the specification (1)-(2),

$$
\mathrm{y}_{\mathrm{i}}^{+}\left(\mathrm{Y}, \mathrm{v}_{\mathrm{i}}\right)=\left[\alpha_{1}-\alpha_{2} \mathrm{Y}-\mathrm{c}_{1 \mathrm{i}}\right] /\left[\mathrm{c}_{2}+\alpha_{2}\left(1+\mathrm{v}_{\mathrm{i}}\right)\right] \text { if } \mathrm{c}_{1 \mathrm{i}} \leq \mathrm{K}_{\mathrm{i}}\left(\mathrm{Y}, \mathrm{c}_{0 \mathrm{i}}, \mathrm{v}_{\mathrm{i}}\right) \text {, }
$$

$$
=0, \text { otherwise, }
$$


where $\left[\mathrm{c}_{2}+\alpha_{2}\left(1+\mathrm{v}_{\mathrm{i}}\right)\right]>0$, and $\mathrm{K}_{\mathrm{i}}\left(\mathrm{Y}, \mathrm{c}_{0 \mathrm{i}}, \mathrm{v}_{\mathrm{i}}\right) \equiv \alpha_{1}-\alpha_{2} \mathrm{Y}-\sqrt{\mathrm{c}_{0 \mathrm{i}}} \frac{\mathrm{c}_{2}+\alpha_{2}\left(1+\mathrm{v}_{\mathrm{i}}\right)}{\sqrt{1 / 2 \mathrm{c}_{2}+\alpha_{2}\left(1+\mathrm{v}_{\mathrm{i}}\right)}}$, with $\partial \mathrm{K}_{\mathrm{i}} / \partial \mathrm{Y}<0$ and $\partial \mathrm{K}_{\mathrm{i}} / \partial \mathrm{v}_{\mathrm{i}}<0(=0)$ when $\mathrm{c}_{0 \mathrm{i}}>0(=0), \mathrm{i} \in \mathrm{M}$.

Conditional on $\mathrm{Y}$ and on firm conduct $\mathrm{v}_{\mathrm{i}}$, equations $(5 \mathrm{a})-(5 \mathrm{~b})$ give the optimal decision of the $\mathrm{i}$-th firm whether it is active or not. These equations show that the $\mathrm{i}$-th firm would become inactive (with $\mathrm{y}_{\mathrm{i}}^{+}\left(\mathrm{Y}, \mathrm{v}_{\mathrm{i}}\right)=0$ ) when the marginal cost parameter $\mathrm{c}_{1 \mathrm{i}}$ is sufficiently high (implying that $\mathrm{y}_{\mathrm{i}}^{\mathrm{a}}\left(\mathrm{Y}, \mathrm{v}_{\mathrm{i}}\right) \leq 0$ ), or if profit $\pi_{\mathrm{i}}^{\mathrm{a}}\left(\mathrm{Y}, \mathrm{v}_{\mathrm{i}}\right)$ becomes negative (e.g., due to high fixed cost $\left.\mathrm{c}_{0 \mathrm{i}}\right)$. Similarly, the constraint $\mathrm{c}_{1 \mathrm{i}} \leq \mathrm{K}_{\mathrm{i}}\left(\mathrm{Y}, \mathrm{c}_{0 \mathrm{i}}, \mathrm{v}_{\mathrm{i}}\right)$ in $(5 \mathrm{~b})$ imposes the non-negativity of firm profit: $\pi_{\mathrm{i}}^{\mathrm{a}}\left(\mathrm{Y}, \mathrm{v}_{\mathrm{i}}\right) \geq 0$. It gives the intuitive result that the $\mathrm{i}$-th firm would be active (with $\mathrm{y}_{\mathrm{i}}^{+}\left(\mathrm{Y}, \mathrm{v}_{\mathrm{i}}\right)>0$ ) only if both marginal cost and fixed cost are "not too high." Note that (5b) implies that $\partial \mathrm{y}_{\mathrm{i}}^{+} / \partial \mathrm{Y}<0$, (Note 5) and $\partial \mathrm{y}_{\mathrm{i}}^{+} / \partial \mathrm{v}_{\mathrm{i}}<0$ for all active firms.

Since equation (5b) identifies which firm is active, it can be used to characterize market equilibrium under firm entry/exit, including the equilibrium number of active firms. (Note 6) Throughout, we take the number m of potential firms and the distribution function $\mathrm{F}\left(\tilde{\mathrm{c}}_{0}, \tilde{\mathrm{c}}_{1}\right)$ as exogenous.

We assume that $\mathrm{F}\left(\tilde{\mathrm{c}}_{0}, \tilde{\mathrm{c}}_{1}\right)$ is a continuous distribution function. This assumption is particularly convenient for our analysis (e.g., it was also made by Melitz). It simplifies the characterization of market equilibrium (see below). With a finite number of firms, $\mathrm{F}\left(\tilde{\mathrm{c}}_{0}, \tilde{\mathrm{c}}_{1}\right)$ being a continuous function means that the cost structure of the i-th firm needs to be characterized by a neighborhood $\left(\Delta_{i 0}, \Delta_{i 1}\right) \subset R_{+}^{2}$, where $F$ is a mapping from $\cup_{i \in M}\left(\Delta_{i 0}, \Delta_{i 1}\right)$ to $[0,1]$. For "fully active" firms that make positive profit, this makes no substantial difference: $\left(\mathrm{c}_{0 \mathrm{i}}, \mathrm{c}_{1 \mathrm{i}}\right)$ in equation (5b) just needs to be reinterpreted as a "representative point" in $\left(\Delta_{i 0}, \Delta_{i 1}\right)$ that exactly replicates the behavior of the $\mathrm{i}$-th firm, $\mathrm{i} \in \mathrm{M}$. But it makes a difference for "marginal firms". Marginal firms are firms that are trying to enter the industry while exhibiting "near-zero" profit. They belong to the set $\cap_{\mathrm{j} \in \mathrm{M}}\left\{\mathrm{j}: \sum_{\mathrm{i} \in(\mathrm{M}-\mathrm{j})} \mathrm{y}_{\mathrm{i}}^{+}\left(\mathrm{Y}^{+}, \mathrm{v}_{\mathrm{i}}\right)<\mathrm{Y}^{+}<\sum_{\mathrm{i} \in \mathrm{M}} \mathrm{y}_{\mathrm{i}}^{+}\left(\mathrm{Y}^{+}, \mathrm{v}_{\mathrm{i}}\right), \mathrm{Y}^{+} \in \operatorname{argmax} \mathrm{Y}_{\mathrm{Y} \geq 0}\left\{\sum_{\mathrm{i} \in \mathrm{M}}\right.\right.$ $\mathrm{y}_{\mathrm{i}}^{+}\left(\mathrm{Y}, \mathrm{v}_{\mathrm{i}}\right) \leq \mathrm{Y}$ \}. Treating $\mathrm{F}\left(\tilde{\mathrm{c}}_{0}, \tilde{\mathrm{c}}_{1}\right)$ as a continuous function amounts to allowing the marginal firm(s) to enter (or exit) the industry "slowly" by producing only a fraction of their "fully active" output. By allowing the marginal firm(s) to be "partially active", it means that the number of active firms can be measured as a real number (instead of an integer).

Let the vector $\mathrm{v}=\left(\mathrm{v}_{1}, \ldots, \mathrm{v}_{\mathrm{m}}\right) \in \mathrm{V}_{\mathrm{m}} \equiv[-1, \infty]^{\mathrm{m}}$ represent the conduct of all firms. Then, conditional on $\mathrm{v}$, define market equilibrium as

$\mathrm{Y}^{*}(\mathrm{v}) \equiv \operatorname{Max}_{\mathrm{Y}}\left\{\mathrm{Y}: \mathrm{Y} \leq \mathrm{S}(\mathrm{Y}, \mathrm{v}), \mathrm{Y} \in \mathrm{R}^{+}\right\}$

where $\mathrm{S}(\mathrm{Y}, \mathrm{v})$ is the aggregate production defined as (using equation $(5 \mathrm{~b})$ ):

$$
\mathrm{S}(\mathrm{Y}, \mathbf{v}) \equiv \mathrm{m} \int_{\tilde{\mathrm{c}}_{0}} \int_{\tilde{\mathrm{c}}_{1} \leq \mathrm{K}(\cdot)}\left[\alpha_{1}-\alpha_{2} \mathrm{Y}-\widetilde{\mathrm{c}}_{1}\right] /\left[\mathrm{c}_{2}+\alpha_{2}\left(1+\mathrm{v}_{\mathrm{i}}\right)\right] \mathrm{dF}\left(\widetilde{\mathrm{c}}_{0}, \widetilde{\mathrm{c}}_{1}\right)
$$

with $\quad \tilde{\mathrm{c}}_{1} \leq \mathrm{K}(\cdot)$ denoting the non-negative profit constraints $\left\{\tilde{\mathrm{c}}_{1} \leq \mathrm{K}_{\mathrm{i}}\left(\mathrm{Y}, \tilde{\mathrm{c}}_{0}, \mathrm{v}_{\mathrm{i}}\right):\left(\tilde{\mathrm{c}}_{0}, \tilde{\mathrm{c}}_{1}\right) \in\left(\Delta_{\mathrm{i} 0}, \Delta_{\mathrm{i} 1}\right), \mathrm{i} \in \mathrm{M}\right\}$.

For a given $v$, equation $(6 a)$ identifies $\mathrm{Y}^{*}(\mathrm{v})$ as the largest aggregate demand where feasibility holds, i.e. where aggregate demand does not exceed aggregate supply. $\mathrm{F}\left(\tilde{\mathrm{c}}_{0}, \tilde{\mathrm{c}}_{1}\right)$ being a continuous distribution function, it follows from $(6 \mathrm{~b})$ that $\mathrm{S}(\mathrm{Y}, \mathbf{v})$ is continuous and decreasing in $\mathrm{Y}$, and that the maximization problem in $(6 \mathrm{a})$ has a unique solution $\mathrm{Y}^{*}(\mathbf{v})$ satisfying $\mathrm{Y}^{*}(\mathbf{v})=\mathrm{S}\left(\mathrm{Y}^{*}(\mathbf{v}), \mathbf{v}\right)$. For a given $\mathbf{v}$, this implies both the existence and uniqueness of market equilibrium.

In turn, from (5a)-(5b) and conditional on $v$, it follows that the market equilibrium production decision of the i-th "fully active" firm is given by

$\mathrm{y}_{\mathrm{i}}^{*}(\mathrm{v})=\mathrm{y}_{\mathrm{i}}^{+}\left(\mathrm{Y}^{*}(\mathrm{v}), \mathrm{v}_{\mathrm{i}}\right)$,

$\mathrm{i} \in \mathrm{M}$. And the number of active firms in the industry is represented by the real number $\mathrm{n}$ satisfying

$\mathrm{n}^{*}(\mathrm{v}) \equiv \mathrm{n}\left(\mathrm{Y}^{*}(\mathrm{v}), \mathrm{v}\right)$,

where

$$
\mathrm{n}(\mathrm{Y}, \mathbf{v}) \equiv \mathrm{m} \int_{\tilde{\mathrm{c}}_{0}} \int_{\tilde{\mathrm{c}}_{1} \leq \mathrm{K}(\cdot)} \mathrm{dF}\left(\tilde{\mathrm{c}}_{0}, \tilde{\mathrm{c}}_{1}\right)
$$

where again $\tilde{\mathrm{c}}_{1} \leq \mathrm{K}(\cdot)$ denotes the non-negative profit constraints. 
Allowing for entry/exit of heterogeneous firms, equations (6a) and (8a) define the market equilibrium of the industry, conditional on firms conduct $v$. This includes the aggregate quantity $\mathrm{Y}^{*}(\mathrm{v})$ given in $(6 \mathrm{a})$ as well as the number of active firms $n^{*}(v)$ given in (8a). The determinants of $v$ will be examined in sections 3-4 below.

What are the implications of the firms' conduct $v$ for aggregate welfare? Consider the case where all active firms make a positive profit and aggregate welfare is measured by the total surplus:

$$
\mathrm{W}=\int_{0}^{\mathrm{Y}^{*}(\mathrm{v})} \mathrm{p}(\mathrm{z}) \mathrm{dz}-\sum_{\mathrm{i} \in \mathrm{M}} \mathrm{C}_{\mathrm{i}}\left(\mathrm{y}_{\mathrm{i}}^{*}(\mathbf{v})\right)
$$

Then, using equations (4a) and (7), the welfare impact of a change in the conduct $v_{i}$ of the $i$-th active firm is given by $\partial \mathrm{W} / \partial \mathrm{v}_{\mathrm{i}}=\sum_{\mathrm{j} \in \mathrm{M}}\left[\mathrm{p}(\mathrm{Y})-\partial \mathrm{C}_{\mathrm{j}}\left(\mathrm{y}_{\mathrm{j}}\right) / \partial \mathrm{y}_{\mathrm{j}}\right]\left(\mathrm{dy}_{\mathrm{j}}{ }^{*} / \mathrm{dv}_{\mathrm{i}}\right)$, evaluated at $\mathrm{Y}^{*}(\mathrm{v})$ and $\left\{\mathrm{y}_{\mathrm{i}}^{*}(\mathrm{v}): \mathrm{i} \in \mathrm{M}\right\}$,

$=0$ if $\mathrm{v}_{\mathrm{j}}=-1$ for all active firms,

$$
<0 \quad \text { if } \mathrm{v}_{\mathrm{i}}>-1, \mathrm{dy}_{\mathrm{i}}^{*} / \mathrm{dv}_{\mathrm{i}}<0 \text {, and } \mathrm{v}_{\mathrm{j}} \geq-1, \mathrm{dy}_{\mathrm{j}}^{*} / \mathrm{dv}_{\mathrm{i}} \leq 0 \text { for all } \mathrm{j} \neq \mathrm{i} \text {. }
$$

This gives the well known result that, to the extent that it contributes to a reduction in supply, (Note 7) any increase in the exercise of market power (as reflected by a rise in $v_{i}$ from -1) has adverse effects on aggregate welfare. The presence of these adverse effects helps motivate the analysis of the determinants of firms' conduct, as investigated next.

\section{The determination of firms' conduct}

The previous section has investigated how firms' conduct $\mathrm{v}$ affects market equilibrium. This section explores the reverse linkages: how industry structure affects firms' conduct. Such linkages are at the core of the traditional Structure-Conduct-Performance approach to industrial organization (e.g., Scherer). We analyze how the number $n$ of active firms in the industry influences the firms' ability to exercise market power and affect markups (as represented by $\mathrm{v}$ ). While this section treats the number of active firms $\mathrm{n}$ as given, note that the joint determination of $\mathrm{n}$ and $\mathrm{v}$ will be addressed in section 4 below.

We assume that the firms behave non-cooperatively, where each firm chooses its own conduct independently of others. (Note 8) Under firm heterogeneity, we investigate the case where firms learn by experimenting with their own conduct and its effect on firm profit. While each firm can choose alternative strategies in the short run, our focus is on the long run, as firms' decisions about their own conduct evolve toward a steady state equilibrium. We show that the behavior of the firms converges as each firm eventually "discovers" what works best for itself. In analyzing the properties of long run equilibrium conduct, we obtain useful insights into the linkages between industry structure and firms' conduct.

In presenting our arguments, we will make use of the properties of "reactions functions" representing interactions among active firms in the industry. Let the set of active firms be $N=\left\{j: y_{j}>0, j \in M\right\} \subset M$. Treating $N$ as given, consider the market clearing condition: $Y=y_{i}+x_{i}$, where $x_{i} \equiv \sum_{j \neq i} y_{j}$ denotes the production of all firms but the $i$-th one. Let $I_{j}=1$ for "fully active" firms producing a positive output and generating a positive profit, let $I_{j}=0$ for inactive firms, and let $I_{j} \in$ $(0,1)$ denote the fraction of output produced by the "partially active" marginal firm(s) (as discussed above). Taking the industry structure $\mathrm{N}$ as given, it follows that

$\mathrm{x}_{\mathrm{i}}=\sum_{\mathrm{j} \neq \mathrm{i}} \mathrm{I}_{\mathrm{j}} \mathrm{y}_{\mathrm{j}}^{+}\left(\mathrm{y}_{\mathrm{i}}+\mathrm{x}_{\mathrm{i}}, \mathrm{v}_{\mathrm{j}}\right)$,

which can be solved for $x_{i}$, giving the reaction functions $x_{i}^{r}\left(y_{i}, v_{N-i}\right)$, where $v_{N-i}=\left\{v_{j}: j \neq i, j \in N\right\}, i \in N$.

Note that $\mathrm{x}_{\mathrm{i}}^{\mathrm{r}}\left(\mathrm{y}_{\mathrm{i}}, \mathrm{v}_{\mathrm{N}-\mathrm{i}}\right)$ depends on the conduct of all active firms except the i-th one. For a given $\mathrm{N}$, the function $\mathrm{x}_{\mathrm{i}}^{\mathrm{r}}\left(\mathrm{y}_{\mathrm{i}}, \mathrm{v}_{\mathrm{N}-\mathrm{i}}\right)$ satisfying (10) measures the equilibrium reaction of other firms, $x_{i}$, to the decision of the $i$-th active firm, $y_{i}, i \in N$. In general, the reaction function $\mathrm{x}_{\mathrm{i}}^{\mathrm{r}}\left(\mathrm{y}_{\mathrm{i}}, \mathrm{v}_{\mathrm{N}-\mathrm{i}}\right)$ depends on $\mathrm{y}_{\mathrm{i}}$, its slope $\partial \mathrm{x}_{\mathrm{i}}^{\mathrm{r}}\left(\mathrm{y}_{\mathrm{i}}, \mathrm{v}_{\mathrm{N}-\mathrm{i}}\right) / \partial \mathrm{y}_{\mathrm{i}}$ measuring the marginal response of other firms to the $\mathrm{i}$-th firm production, $\mathrm{i} \in \mathrm{N}$. (Note 9)

We now analyze the determinants of conduct $\mathrm{v}_{\mathrm{N}}=\left\{\mathrm{v}_{\mathrm{j}}: \mathrm{j} \in \mathrm{N}\right\} \in \mathrm{V}_{\mathrm{N}}$, where the feasible set $\mathrm{V}_{\mathrm{N}}$ restricts each $\mathrm{v}_{\mathrm{j}}$ to be in the interval $[-1, \infty]$. The questions are: How does firms' conduct $\mathrm{v}_{\mathrm{N}}$ change over time? And to what values might it converge in the long run? Denote the i-th firm profit by: $\pi_{i}\left(y_{i}, x_{i}\right) \equiv p\left(y_{i}+x_{i}\right) y_{i}-C_{i}\left(y_{i}\right)$. We make the following assumption:

Assumption A1: At time $t$, denote the conduct of the $n$ active firms by $v_{N, t}=\left(v_{1, t}, \ldots, v_{n, t}\right)$. Assume that the conduct of the $i$-th firm evolves over time as follows

$\mathrm{v}_{\mathrm{i}, \mathrm{t}+1}\left(\mathrm{v}_{\mathrm{N}-\mathrm{i}, \mathrm{t}}\right)=\left(1-\beta_{\mathrm{vi}, \mathrm{t}}\right) \mathrm{v}_{\mathrm{i}, \mathrm{t}}+\beta_{\mathrm{vi}, \mathrm{t}} \mathrm{v}_{\mathrm{i}}^{+}\left(\mathrm{v}_{\mathrm{N}-\mathrm{i}, \mathrm{t}}\right)$,

where 


$$
\mathrm{v}_{\mathrm{i}}^{+}\left(\mathrm{v}_{\mathrm{N}-\mathrm{i}, \mathrm{t}}\right) \in \operatorname{argmax}_{\mathrm{vi}}\left\{\pi_{\mathrm{i}}\left(\mathrm{y}_{\mathrm{i}}^{*}\left(\mathrm{v}_{\mathrm{N}, \mathrm{t}}\right), \mathrm{x}_{\mathrm{i}}^{\mathrm{r}}\left(\mathrm{y}_{\mathrm{i}}^{*}\left(\mathrm{v}_{\mathrm{N}, \mathrm{t}}\right), \mathrm{v}_{\mathrm{N}-\mathrm{i}, \mathrm{t}}\right): \mathrm{v}_{\mathrm{N}, \mathrm{t}} \in \mathrm{V}_{\mathrm{N}}\right\},\right.
$$

with $\beta_{\mathrm{vi}, \mathrm{t}} \in[\varepsilon, 1]$ for some $\varepsilon \in(0,1], \mathrm{i} \in \mathrm{N}$.

Assumption A1 states that each active firm will modify its current conduct $\mathrm{v}_{\mathrm{i}, \mathrm{t}}$ in the direction of increasing its profit. This seems both intuitive and reasonable. It is quite general. Under non-cooperative behavior, it lets each active firm choose its own conduct. It allows for alternative short-term firm conduct and its evolution over time. And it allows for complex interactions among firms.

Below, we focus our attention on long-term equilibrium of firms' conduct generated from the evolutionary dynamics in (11a)-(11b). Under assumption A1, firms' conduct evolves over time as $\mathrm{v}_{\mathrm{N}, \mathrm{t}+1}\left(\mathrm{v}_{\mathrm{N}, \mathrm{t}}\right) \equiv\left(\mathrm{v}_{1, t+1}\left(\mathrm{v}_{\mathrm{N}-1, t}\right), \ldots, \mathrm{v}_{\mathrm{n}, \mathrm{t}+1}\left(\mathrm{v}_{\mathrm{N}-1, \mathrm{t}}\right)\right)$, where $\mathrm{v}_{\mathrm{i}, \mathrm{t}+1}\left(\mathrm{v}_{\mathrm{N}-\mathrm{i}, \mathrm{t}}\right)$ is given in (11a). For some initial condition $\mathrm{v}_{\mathrm{N}, 0}$, the forward path of firms' conduct is $\mathrm{v}_{\mathrm{N}, \mathrm{t}}{ }^{*}\left(\mathrm{v}_{\mathrm{N}, 0}\right)=\mathrm{v}_{\mathrm{N}, \mathrm{t}}\left(\mathrm{v}_{\mathrm{N}, \mathrm{t}-1}(\ldots\right.$ $\left.\left.\mathrm{v}_{\mathrm{N}, 1}\left(\mathrm{v}_{\mathrm{N}, 0}\right)\right)\right)$. Assuming that it exists, consider the limit $\mathrm{v}^{*}(\mathrm{~N}) \equiv\left(\mathrm{v}_{1}{ }^{*}(\mathrm{~N}), \ldots, \mathrm{v}_{\mathrm{n}}{ }^{*}(\mathrm{~N})\right) \equiv \lim _{\mathrm{t} \rightarrow \infty} \mathrm{v}_{\mathrm{N}, \mathrm{t}}{ }^{*}\left(\mathrm{v}_{\mathrm{N}, 0}\right)$. This identifies the long-run conduct of active firms $\left\{\mathrm{v}_{\mathrm{i}}{ }^{*}(\mathrm{~N}): \mathrm{i} \in \mathrm{N}\right\}$ in a steady sate equilibrium under free entry/exit, conditional on industry structure $\mathrm{N}$. Note that it allows the conduct $\mathrm{v}_{\mathrm{i}}{ }^{*}(\mathrm{~N})$ to vary across firms. Under (11a)-(11b) and conditional on the number $\mathrm{n}$ of active firms, the existence, uniqueness and analytical properties of this long run equilibrium are investigated next (See the proof in the Appendix).

Proposition 1: For a given set $\mathrm{N}$ of active firms, assume that A1 holds. Under the specification (1)-(2),

- A long run steady state equilibrium for conduct $\mathrm{v}_{\mathrm{N}}$ exists and is unique.

- The long run steady state equilibrium for $\mathrm{v}_{\mathrm{N}}$ is given by $\mathrm{v}_{\mathrm{i}}^{*}=\frac{\partial \mathrm{x}_{\mathrm{i}}^{\mathrm{r}}}{\partial \mathrm{y}_{\mathrm{i}}}\left(\mathrm{y}_{\mathrm{i}}, \mathbf{v}_{\mathrm{N}-\mathrm{i}}\right), \mathrm{i} \in \mathrm{N}$.

- The $\mathrm{v}_{\mathrm{i}}^{*}$ 's are the same for all active firms and satisfy

$$
\mathrm{v}_{\mathrm{i}}^{*}=\mathrm{v}^{*}(\mathrm{n})=-1 / 2\left(\mathrm{n}+\mathrm{c}_{2} / \alpha_{2}\right)+1 / 2 \sqrt{\left(\mathrm{n}+\mathrm{c}_{2} / \alpha_{2}\right)^{2}-4(\mathrm{n}-1)},
$$

$\mathrm{i} \in \mathrm{N}$, with

$$
\partial \mathrm{v}^{*} / \partial \mathrm{n}=-1 / 2+\frac{1 / 2\left(\mathrm{n}+\mathrm{c}_{2} / \alpha_{2}\right)-1}{\sqrt{\left(\mathrm{n}+\mathrm{c}_{2} / \alpha_{2}\right)^{2}-4(\mathrm{n}-1)}} .
$$

Conditional on $\mathrm{n}$, proposition 1 establishes the existence and uniqueness of a long run equilibrium for firms' conduct. And it provides a formal linkage between market structure (as represented by n) and firms' conduct (as represented by $\left.\mathrm{v}^{*}(\mathrm{n})\right)$.

Note that $\mathrm{v}_{\mathrm{i}}^{*}=\frac{\partial \mathrm{x}_{\mathrm{i}}^{\mathrm{r}}}{\partial \mathrm{y}_{\mathrm{i}}}\left(\mathrm{y}_{\mathrm{i}}, \mathbf{v}_{\mathrm{N}-\mathrm{i}}\right)$ implies that the $\mathrm{v}_{\mathrm{i}}^{*}$ 's are also the consistent conjectures discussed by Bresnahan, Perry, and Dixit (1986). Thus, Proposition 1 shows that the long run equilibrium leads to consistent conjectures among active firms. Dixon and Somma, and Müeller and Normann obtained similar results in the context of duopoly (where $n=2$ ). Thus, Proposition 1 generalizes their results to oligopoly situations, with an arbitrary number of heterogeneous firms. It provides an economic rational for consistent conjectures. Indeed, under the specification (1)-(2), Proposition 1 shows that, if more profitable conjectures tend to become more common, identical consistent conjecture is the unique evolutionary stable strategy. Under assumption A1, this applies irrespective of the firms' short-term strategies. In this context, identical consistent conjectures emerge in the long run through evolutionary selection over time.

Equations (12) and (13) show analytically how the firms' conduct $v^{*}$ varies with the structural parameters $\left(c_{2} / \alpha_{2}\right)$ and the number of active firms in the industry (n). The relationship between $v^{*}$ and $n$ is of particular interest as it makes firms' conduct depend on industry structure. Equations (12)-(13) imply the following results.

Corollary 1: Under the specification (1)-(2) with $\mathrm{n} \geq 1$,

a) the firms' conduct $v^{*}(n)$ satisfies $-1 \leq v^{*} \leq 0$, with

$$
\mathrm{v}^{*}=0 \text { if } \mathrm{n}=1 \text {, }
$$




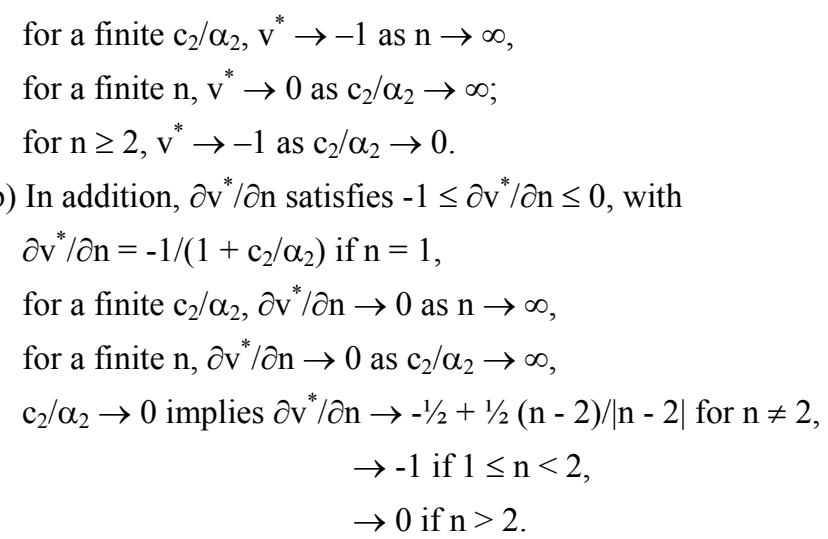

Corollary 1 establishes the properties of conduct $\mathrm{v}^{*}(\mathrm{n})$ as the number $\mathrm{n}$ of active firms changes. From a), $\mathrm{v}^{*}$ is in general non-positive and bounded between -1 and 0 . It attains its lower bound $\left(\mathrm{v}^{*}=-1\right)$ when the number $\mathrm{n}$ of active firms is large. This corresponds to Bertrand competition, where firms anticipate no price response from changing supply. And the conduct $\mathrm{v}^{*}(\mathrm{n})$ attains its upper bound $(\mathrm{v}=0)$ under monopoly (with $\left.\mathrm{n}=1\right)$. In between these two extremes, increasing the number $n$ of active firms tends to reduce $v^{*}\left(\partial v^{*} / \partial n \leq 0\right.$ from $\left.\left.b\right)\right)$. This is intuitive: the potential to exercise market power becomes stronger (weaker) when the number of active firms is smaller (larger).

In addition, from Corollary $1 \mathrm{a}$, the firms' conduct $\mathrm{v}^{*}$ tends to 0 when $\mathrm{c}_{2} / \alpha_{2}$ becomes large. This corresponds to cases where marginal cost is rising sharply $\left(\mathrm{c}_{2}=\right.$ large) and/or where demand is very price-responsive (with $|\partial \mathrm{Y} / \partial \mathrm{p}|=1 / \alpha_{2}=$ large). In such situations, as long as the number $\mathrm{n}$ of active firms is finite, Cournot pricing is (approximately) satisfied irrespective of industry structure. (Note 10) Alternatively, given $n \geq 2$, firms' conduct $v^{*}(n)$ tends to -1 when $c_{2} / \alpha_{2}$ becomes close to 0 . This includes cases where marginal cost is constant $\left(c_{2}=0\right.$, with large supply response), (Note 11$)$ and/or where demand exhibits little price responsiveness (with $|\partial \mathrm{Y} / \partial \mathrm{p}|=1 / \alpha_{2}=$ small). In such situations, as long as $\mathrm{n} \geq$ 2 , Bertrand competition is (approximately) satisfied irrespective of industry structure. Finally, from Corollary $1 \mathrm{~b}$, the marginal effect of $n$ on $\mathrm{v}^{*}$ becomes small $\left(\partial \mathrm{v}^{*} / \partial \mathrm{n} \rightarrow 0\right)$ when $\mathrm{c}_{2} / \alpha_{2}$ is close to zero and $\mathrm{n}>2$. And $\partial \mathrm{v}^{*} / \partial \mathrm{n} \rightarrow 0$ when $\mathrm{c}_{2} / \alpha_{2}$ becomes very large. It means that, when $n>2$, changes in industry structure (i.e., changes in $n$ ) affect firms' conduct only in situations where $c_{2} / \alpha_{2}$ takes on moderate values (i.e., neither too small nor too large). For example, assuming constant marginal cost (with $\mathrm{c}_{2} \rightarrow 0$ ) would basically remove the possibility for firms to exercise market power when $n>2$ (Kamien and Schwartz). This stresses the importance of the cost structure in the study of oligopoly behavior.

A contestable market has been associated with free entry and exit, identical producers, and potential entrants exhibiting Bertrand pricing (Baumol et al.). Note that identical firms are obtained as a special case of our model when $\mathrm{c}_{0 \mathrm{i}}$ and $\mathrm{c}_{1 \mathrm{i}}$ are the same for all firms. Corollary 1 shows how firms' conduct can generate Bertrand competition. Bertrand pricing (with $\mathrm{v}=-1$ ) can be obtained under at least two scenarios. First, from Corollary $1 \mathrm{a}, \mathrm{v}^{*}=-1$ if the number $\mathrm{n}$ of active firms is sufficiently large. Second, Bertrand competition $(v=-1)$ is generated under constant marginal cost (where $\left.c_{2} \rightarrow 0\right)$ when $n \geq 2$. In either scenario, under entry and exit, a contestable market would arise in long run equilibrium. The first scenario $(\mathrm{n}=$ large $)$ is the classical case of a competitive market. The second scenario arises under more general conditions: as long as marginal cost is constant, it applies under various industry structures exhibiting at least two active firms $(n \geq 2)$. In contrast to Baumol et al., note that our approach does not assume Bertrand pricing.

These results are illustrated in Figure 1, which presents the function $\mathrm{v}^{*}(\mathrm{n})$ for selected values of the parameters $\mathrm{k} \equiv \mathrm{c}_{2} / \alpha_{2}$. Figure 1 shows how Bertrand pricing can apply under general conditions when $c_{2} / \alpha_{2}$ is small. This documents how Bertrand/competitive pricing can arise over time through evolutionary selection even when the number of active firms remains relatively small. However, Figure 1 also indicates how firm conduct can depart from Bertrand pricing when the ratio $c_{2} / \alpha_{2}$ rises. Again, this illustrates how the cost structure can affect the exercise of market power.

\section{Industry Behavior}

In this section, we explore long run industry behavior with a focus on the joint determination of firms' conduct/markup and firm entry/exit under the specification given in (1)-(2). Recall that we allow for cost heterogeneity among firms, where the distribution of the cost parameters $\left(\tilde{\mathrm{c}}_{0}, \tilde{\mathrm{c}}_{1}\right)$ is given by the distribution function $\mathrm{F}\left(\tilde{\mathrm{c}}_{0}, \tilde{\mathrm{c}}_{1}\right)$. Below, we investigate how changes in the cost structure affect industry equilibrium. We will focus our attention on changes in $\overline{\mathrm{c}}_{0}$, the mean of fixed cost $\tilde{\mathrm{c}}_{0}$, and in $\overline{\mathrm{c}}_{1}$, the mean of variable cost $\tilde{\mathrm{c}}_{1}$ across all firms (including both active firms and potential entrants) in the industry. Changes in the mean $\overline{\mathrm{c}}_{0}$ (or $\overline{\mathrm{c}}_{1}$ ) are equivalent to changes in $\tilde{\mathrm{c}}_{0}$ (or $\tilde{\mathrm{c}}_{1}$ ) affecting all firms in the industry. Such focus will be of interest below as the aggregate effects of changes in cost affecting a subset of firms 
are qualitatively similar to the corresponding effects when all firms are affected. In the next section, this will allow us to interpret our results in the context of evaluating market globalization issues.

To simplify our analysis, we assume that the distribution function $\mathrm{F}\left(\tilde{\mathrm{c}}_{0}, \tilde{\mathrm{c}}_{1}\right)$ is twice differentiable. In this context, we analyze long run industry behavior under three scenarios: 1) the case where the firms' conduct $v$ is exogenous; 2) the long run equilibrium case when $\mathrm{v}$ is endogenous under long run equilibrium, but in the absence of fixed cost; and 3) the general case of endogenous firms' conduct in the presence of fixed cost.

\subsection{Case 1: The case of exogenous firms' conduct}

First, we consider long run industry behavior when firms' conduct is treated as given. While restrictive, the analysis of this scenario will provide a stepping-stone toward a more complete analysis of firm conduct and industry behavior presented below. Using the results of Proposition 1, we focus our attention on the case where $v_{i}=v$ for all active firms. Then, conditional on $\mathrm{v}$, the market equilibrium conditions are given by the aggregate quantity $\mathrm{Y}^{*}(\mathrm{v})$ in $(6 \mathrm{a})$, and by the number of active firms $\mathrm{n}^{*}(\mathrm{v})$ in $(8 \mathrm{a})$. The associated equilibrium price is $\mathrm{p}^{*}(\mathrm{v}) \equiv \mathrm{p}\left(\mathrm{Y}^{*}(\mathrm{v})\right)$.

From (6a), the aggregate quantity $\mathrm{Y}^{*}(\mathrm{v})$ is given by the value $\mathrm{Y}$ that satisfies the market equilibrium condition: $\mathrm{Y}=\mathrm{S}(\mathrm{Y}$, $\mathrm{v})$. The properties of $\mathrm{Y}^{*}$ are presented next. They include the effects of changing conduct $\mathrm{v}$, mean fixed cost $\mathrm{c}_{0}$, mean variable cost $\bar{c}_{0}$, as well as the demand shifter $\alpha_{1}$. See the proof in the Appendix.

Lemma 1: The aggregate quantity $\mathrm{Y}^{*}(\mathrm{v})$ in (6a) satisfies

a) $\partial \mathrm{Y}^{*} / \partial \mathrm{v}<0$,

b) $\partial \mathrm{Y}^{*} / \partial \overline{\mathrm{c}}_{0}<0$,

c) $\partial \mathrm{Y}^{*} / \partial \overline{\mathrm{c}}_{1}<0$,

d) $\partial Y^{*} / \partial \alpha_{1} \in\left(0,1 / \alpha_{2}\right)$.

Lemma 1 shows the factors influencing the market equilibrium aggregate quantity $\mathrm{Y}^{*}$ conditional on conduct $\mathrm{v}$. Result a) shows that increasing $\mathrm{v}$ reduces industry supply. Interpreting a rise in $\mathrm{v}$ as an increase in market power gives the intuitive result that the exercise of market power implies a reduction in aggregate supply. Results b) and c) imply that increasing either mean fixed cost $\left(\overline{\mathrm{c}}_{0}\right)$ or marginal cost $\left(\overline{\mathrm{c}}_{1}\right)$ provides a disincentive to produce at the industry level. However, the sources of these adjustments differ. Higher marginal cost has two additive effects: it reduces the supply from incumbent firms; and it provides an incentive for firms to exit (see (B8d) in the Appendix). In contrast, higher fixed cost has only one effect: it just provides an incentive for firms to exit (see (B8c) in the Appendix). Indeed, from equation (5b), fixed cost does not affect the behavior of incumbent firms that remain active and profitable.

Finally, result d) shows that an increase in demand (represented by a rise in $\alpha_{1}$ ) tends to stimulate the market equilibrium aggregate quantity $\mathrm{Y}^{*}(\mathrm{v})$, the marginal impact being bounded between 0 and $1 / \alpha_{2}$.

The price equilibrium $\mathrm{p}^{*}(\mathrm{v})$ is given by $\mathrm{p}^{*}(\mathrm{v}) \equiv \alpha_{1}-\alpha_{2} \mathrm{Y}^{*}(\mathrm{v})$. Using Lemma 1 , we obtain the following results.

Proposition 2: The market equilibrium price $\mathrm{p}^{*}(\mathrm{v})$ satisfies

a) $\partial \mathrm{p}^{*} / \partial \mathrm{v}>0$

b) $\partial \mathrm{p}^{*} / \partial \overline{\mathrm{c}}_{0}>0$

c) $\partial \mathrm{p}^{*} / \partial \overline{\mathrm{c}}_{1}>0$,

d) $\partial \mathrm{p}^{*} / \partial \alpha_{1} \in(0,1)$.

Proposition 2 shows the factors influencing the market equilibrium price $\mathrm{p}^{*}$ conditional on conduct v. Result a) shows that increasing $\mathrm{v}$ increases price. Intuitively, a rise in market power tends to increase markup and price. Results b) and c) imply that increasing either fixed cost $\left(\overline{\mathrm{c}}_{0}\right)$ or marginal cost $\left(\overline{\mathrm{c}}_{1}\right)$ contributes to a higher price. Finally, result d) shows an increase in demand (represented by a rise in $\alpha_{1}$ ) tends to increase price, although the marginal price increase is bounded between 0 and 1 .

The market equilibrium number of active firms $\mathrm{n}^{*}(\mathrm{v}) \equiv \mathrm{n}\left(\mathrm{Y}^{*}(\mathrm{v}), \mathrm{v}\right)$ is given in equations $(8 \mathrm{a})-(8 \mathrm{~b})$. This gives $\partial \mathrm{n}^{*} / \partial\left(\mathrm{v}, \overline{\mathrm{c}}_{0}, \overline{\mathrm{c}}_{1}, \alpha_{1}\right)=\partial \mathrm{n} / \partial\left(\mathrm{v}, \overline{\mathrm{c}}_{0}, \overline{\mathrm{c}}_{1}, \alpha_{1}\right)+(\partial \mathrm{n} / \partial \mathrm{Y})\left(\partial \mathrm{Y}^{*} / \partial\left(\mathrm{v}, \overline{\mathrm{c}}_{0}, \overline{\mathrm{c}}_{1}, \alpha_{1}\right)\right)$, 
Equation (14) decomposes the effect of $\left(\mathrm{v}, \overline{\mathrm{c}}_{0}, \overline{\mathrm{c}}_{1}, \alpha_{1}\right)$ on $\mathrm{n}^{*}$ into two additive components: a direct effect $\partial \mathrm{n} / \partial\left(\mathrm{v}, \overline{\mathrm{c}}_{0}\right.$, $\left.\overline{\mathrm{c}}_{1}, \alpha_{1}\right)$, holding aggregate output $\mathrm{Y}$ constant; and an indirect effect $(\partial \mathrm{n} / \partial \mathrm{Y})\left(\partial \mathrm{Y}^{*} / \partial\left(\mathrm{v}, \overline{\mathrm{c}}_{0}, \overline{\mathrm{c}}_{1}, \alpha_{1}\right)\right)$, capturing the induced adjustment through $Y$. The properties of $n^{*}(v)$ are presented next. See the proof in the Appendix.

Proposition 3: The number of active firms given by $\mathrm{n}(\mathrm{Y}, \mathrm{v})$ and $\mathrm{n}^{*}(\mathrm{v})$ in $(8 \mathrm{a})-(8 \mathrm{~b})$ satisfies

a) $\partial \mathrm{n} / \partial \mathrm{Y}<0$,

b) $\partial \mathrm{n}^{*} / \partial \mathrm{v}>\partial \mathrm{n} / \partial \mathrm{v}=0$ in the absence of fixed cost (where $\mathrm{c}_{0 \mathrm{i}}=0$ for all firms), $<0$ in the presence of fixed cost (where $\mathrm{c}_{0 \mathrm{i}}>0$ for all firms),

c) $0\left\{\begin{array}{l}> \\ = \\ <\end{array}\right\} \partial \mathrm{n}^{*} / \partial\left(\overline{\mathrm{c}}_{0}, \overline{\mathrm{c}}_{1}\right)>\partial \mathrm{n} / \partial\left(\overline{\mathrm{c}}_{0}, \overline{\mathrm{c}}_{1}\right)<0$, as $(\partial \mathrm{n} / \partial \mathrm{Y})\left(\partial \mathrm{Y}^{*} / \partial\left(\overline{\mathrm{c}}_{0}, \overline{\mathrm{c}}_{1}\right)\right)\left\{\begin{array}{l}< \\ =\end{array}\right\}-\partial \mathrm{n} / \partial\left(\overline{\mathrm{c}}_{0}, \overline{\mathrm{c}}_{1}\right)$,

d) $0<\partial \mathrm{n}^{*} / \partial \alpha_{1}<\partial \mathrm{n} / \partial \alpha_{1}=-(\partial \mathrm{n} / \partial \mathrm{Y}) / \alpha_{2}$.

By identifying the factors influencing the number of active firms, Proposition 3 provides useful information on the determinants of entry and exit in the industry (conditional on v). In particular, result b) illustrates the role of fixed cost. It shows two results. First, in the absence of fixed cost, it states that $\partial \mathrm{n}^{*} / \partial \mathrm{v}>0$. In this case, the direct effect in (14) vanishes (with $\partial \mathrm{n} / \partial \mathrm{v}=0$ ), and a higher $\mathrm{v}$ simulating increased market power always induces entry (as it reduces aggregate supply $\left(\partial \mathrm{Y}^{*} / \partial \mathrm{v}<0\right)$, which increases price). Interestingly, in the presence of fixed cost, $\partial \mathrm{n}^{*} / \partial \mathrm{v}$ is not necessarily positive (e.g., it can be negative when the negative direct effect, $\partial \mathrm{n} / \partial \mathrm{v}<0$, dominates the indirect effect in (14)). Second, result b) shows that $\partial \mathrm{n}^{*} / \partial \mathrm{v}>\partial \mathrm{n} / \partial \mathrm{v}$ in general (i.e., with or without fixed cost). It reflects that the indirect effect of $\mathrm{v}$ in (14) is always positive, which tends to make the impact of $\mathrm{v}$ on $\mathrm{n}^{*}$ more positive.

Result c) shows that the effects of cost on the number of active firms $n^{*}$ can be complex. It gives three important findings. First, it states that the direct effect $\partial \mathrm{n} / \partial\left(\overline{\mathrm{c}}_{0}, \overline{\mathrm{c}}_{1}\right)$ is always negative: for a given $\mathrm{Y}$, increasing cost (either fixed or marginal) provides an incentive for firms to exit the industry. Second, result c) shows that $\partial \mathrm{n}^{*} / \partial\left(\overline{\mathrm{c}}_{0}, \overline{\mathrm{c}}_{1}\right)>\partial \mathrm{n} / \partial\left(\overline{\mathrm{c}}_{0}\right.$, $\left.\bar{c}_{1}\right)$. This reflects the fact that the indirect effect in (14) is always positive, $(\partial \mathrm{n} / \partial \mathrm{Y})\left(\partial \mathrm{Y}^{*} / \partial\left(\overline{\mathrm{c}}_{0}, \overline{\mathrm{c}}_{1}\right)\right)>0$ : a higher cost tends to decrease aggregate supply and increase price, which in turn provides an incentive for firms to enter. As a result the net effect of changing $c_{0}$ or $c_{1}$ on the number of active firms $\mathrm{n}^{*}$ can be either negative or positive depending upon whether the direct effect dominates or not. This gives the third finding: $\partial \mathrm{n}^{*} / \partial\left(\overline{\mathrm{c}}_{0}, \overline{\mathrm{c}}_{1}\right)\left\{\begin{array}{l}\Rightarrow \\ \theta\end{array}\right\}$ as $(\partial \mathrm{n} / \partial \mathrm{Y})\left(\partial \mathrm{Y}^{*} / \partial\left(\overline{\mathrm{c}}_{0}, \overline{\mathrm{c}}_{1}\right)\right)$ $-\partial \mathrm{n} / \partial\left(\overline{\mathrm{c}}_{0}, \overline{\mathrm{c}}_{1}\right)$. Under a general cost distribution $\mathrm{F}\left(\tilde{\mathrm{c}}_{0}, \tilde{\mathrm{c}}_{1}\right)$ across firms, this illustrates the complex determination of

long run industry structure under changing cost structure. It also shows that increased cost tends to stimulate exit, $\partial \mathrm{n}^{*} / \partial\left(\overline{\mathrm{c}}_{0}, \overline{\mathrm{c}}_{1}\right)<0$, when the direct effect $\partial \mathrm{n} / \partial\left(\overline{\mathrm{c}}_{0}, \overline{\mathrm{c}}_{1}\right)<0$ dominates in (14). Below, we will call this a "normal situation" mostly on intuitive ground. (Note 12) This will prove relevant in the discussion presented below.

Finally, result d) shows that the net effect of expanding demand (as represented by the parameter $\alpha_{1}$ ) on the number of firms $n^{*}(v)$ is unambiguously positive. And its marginal effect $\partial \mathrm{n}^{*} / \partial \alpha_{1}$ is bounded between 0 and $-(\partial \mathrm{n} / \partial \mathrm{Y}) / \alpha_{2}$.

\subsection{Case 2: The case of endogenous firms' conduct in the absence of fixed cost}

Case 1 has examined the properties of industry behavior holding the firms' conduct $v$ constant. Under entry/exit, it has allowed the number of firms in the industry to adjust in response to changes in cost or demand. But holding $\mathrm{v}$ constant is restrictive: firms' conduct/markups can clearly change with the structure of the industry. We now extend the analysis to the case where conduct $\mathrm{v}$ is endogenous. Relying on Proposition 1, we focus our attention on the long run equilibrium conduct, i.e., on the firms' conduct given by $\mathrm{V} *(\mathrm{n})$ in equation (12).

"Case 2" restricts the analysis to situations where there is no fixed cost. This provides an important simplification. From Proposition $3 b$, in the absence of fixed cost, the number of active firms $n(Y, v)$ in (8) no longer depends on $v$. Then, market equilibrium is given by equations $(8)$ and $(12)$, where $\mathrm{Y}=\mathrm{S}\left(\mathrm{Y}, \mathrm{v}^{*}(\mathrm{n}(\mathrm{Y}))\right.$. Define $\mathrm{S}^{*}(\mathrm{Y}) \equiv \mathrm{S}\left(\mathrm{Y}, \mathrm{v}^{*}(\mathrm{n}(\mathrm{Y}))\right)$. It 
follows that the market equilibrium aggregate quantity is the solution $\mathrm{Y}^{\mathrm{e}}$ to the equation $\mathrm{Y}=\mathrm{S}^{*}(\mathrm{Y})$. Note that $\mathrm{S}(\mathrm{Y}, \mathrm{v})$ is decreasing in $\mathrm{Y}$ and $\mathrm{v}$. In addition, $\mathrm{v}^{*}(\mathrm{n})$ is non-increasing in $\mathrm{n}$ (from Corollary $1 \mathrm{~b}$ ) and $\mathrm{n}(\mathrm{Y})$ is decreasing in $\mathrm{Y}$ (from Proposition 3a). It follows that $S^{*}(Y)$ is decreasing in $Y$. Under assumption A1, this implies that $Y=S^{*}(Y)$ has a unique solution $\mathrm{Y}^{\mathrm{e}}$. Then, the market price is $\mathrm{p}^{\mathrm{e}}=\alpha_{1}-\alpha_{2} \mathrm{Y}^{\mathrm{e}}$, the equilibrium number of firms is $\mathrm{n}^{\mathrm{e}}=\mathrm{n}\left(\mathrm{Y}^{\mathrm{e}}\right)$, and the long run equilibrium conduct is $\mathrm{v}^{\mathrm{e}}=\mathrm{v}\left(\mathrm{n}^{\mathrm{e}}\right)$.

To illustrate the implications, compare the market equilibrium conditions of case 1 and case 2. They are: $\mathrm{Y}=\mathrm{S}(\mathrm{Y}, \mathrm{v})$, where $\mathrm{S}(\mathrm{Y}, \mathrm{v})$ is the equilibrium aggregate supply in case 1 , v being treated as exogenous; and $\mathrm{Y}=\mathrm{S}\left(\mathrm{Y}, \mathrm{v}^{*}(\mathrm{n}(\mathrm{Y}))\right) \equiv \mathrm{S}^{*}(\mathrm{Y})$ in case 2 (i.e., in the absence of fixed cost, and with $\mathrm{v}^{*}(\mathrm{n})$ being given in (12)). The properties of $\mathrm{v}^{*}$ and $\mathrm{n}$ have been examined in Corollary 1 and Propositions 3, respectively. We have

$$
\partial \mathrm{S}^{*} / \partial \mathrm{Y}=\partial \mathrm{S} / \partial \mathrm{Y}+(\partial \mathrm{S} / \partial \mathrm{v})\left(\partial \mathrm{v}^{*} / \partial \mathrm{n}\right)(\partial \mathrm{n} / \partial \mathrm{Y})
$$

where $\partial \mathrm{S} / \partial \mathrm{Y}<0$ from equation $(\mathrm{B} 8 \mathrm{a})$ in the Appendix, $\partial \mathrm{S} / \partial \mathrm{v}<0$ from equation $(\mathrm{B} 8 \mathrm{~b}), \partial \mathrm{v}^{*} / \partial \mathrm{n} \leq 0$ from Corollary $1 \mathrm{~b}$, and $\partial \mathrm{n} / \partial \mathrm{Y}<0$ from Proposition 3a. This generates the following result.

Proposition 4: In the absence of fixed cost $\left(\tilde{c}_{0}=0\right)$, the equilibrium aggregate supply functions $S(Y, v)$ and $S^{*}(Y)$ satisfy

$$
\partial \mathrm{S}^{*} / \partial \mathrm{Y} \leq \partial \mathrm{S} / \partial \mathrm{Y}<0 \text {. }
$$

With $\mathrm{Y}$ being the aggregate quantity demanded, Proposition 4 can be interpreted in terms of the responsiveness of aggregate supply to changing demand conditions. It implies that aggregate supply is more responsive (in absolute value) to changing demand conditions under case 2 than under case 1. It shows that allowing for adjustments in market structure (as represented by $\mathrm{n}(\mathrm{Y})$ ) and in firms' conduct (as represented by $\mathrm{v}^{*}(\mathrm{n})$ in equation (12)) tends to stimulate aggregate supply response. Alternatively, it indicates that neglecting the entry/exit process and the changing structure of an industry, along with the associated changes in firms' conduct, can result in underestimating the magnitude of supply adjustments to changing demand conditions. This stresses the importance of a proper understanding of the entry/exit process and its linkages with firms' conduct.

In addition, under case 2 (where $\tilde{\mathrm{c}}_{0}=0$ in the absence of fixed cost), we have $\partial \mathrm{S} / \partial \mathrm{Y}=-\frac{\mathrm{n}}{\mathrm{c}_{2} / \alpha_{2}+(1+\mathrm{v})}$ from (B8a). Then, equation (15) becomes

$$
\partial \mathrm{S}^{*} / \partial \mathrm{Y}=\frac{\mathrm{n}}{\mathrm{c}_{2} / \alpha_{2}+(1+\mathrm{v})}+(\partial \mathrm{S} / \partial \mathrm{v})\left(\partial \mathrm{v}^{*} / \partial \mathrm{n}\right)(\partial \mathrm{n} / \partial \mathrm{Y})
$$

This shows how industry structure (as represented by the number $\mathrm{n}$ of active firms) relates to the responsiveness of aggregate supply $\partial \mathrm{S}^{*} / \partial \mathrm{Y}$. The first term in (16) indicates that an increase in $\mathrm{n}$ reduces $\partial \mathrm{S} / \partial \mathrm{Y}$, and thus increases the responsiveness of aggregate supply. In addition, when $\mathrm{n}$ is greater than 2 and large and/or $\left(\mathrm{c}_{2} / \alpha_{2}\right)$ is small, then $\mathrm{v}$ approaches -1 (from Corollary 1a), $\left(\partial \mathrm{v}^{*} / \partial \mathrm{n}\right)$ approaches 0 (from Corollary 1b), and the second term in (16) becomes negligible. In this case, any increase in $\mathrm{n}$ always stimulates the responsiveness of supply to changing demand conditions, $\partial \mathrm{S}^{*} / \partial \mathrm{Y}$. This result is summarized next.

Lemma 2: In the absence of fixed cost $\left(\tilde{\mathrm{c}}_{0}=0\right)$, when $\mathrm{n}$ is large and/or $\left(\mathrm{c}_{2} / \alpha_{2}\right)$ is small, then more competitive industry structures (corresponding to an increase in $\mathrm{n}$ ) contribute to stimulating supply response.

Next, we consider the effects of the demand shifter $\alpha_{1}$. In the absence of fixed cost, the market equilibrium is given by the value $\mathrm{Y}^{\mathrm{e}}$ that solves $\mathrm{Y}=\mathrm{S}\left(\mathrm{Y}, \mathrm{v}^{*}(\mathrm{n}(\mathrm{Y}))\right) \equiv \mathrm{S}^{*}(\mathrm{Y})$. Applying the implicit function theorem yields

$\partial \mathrm{Y}^{\mathrm{e}} / \partial \alpha_{1}=\left[1-\partial \mathrm{S}^{*} / \partial \mathrm{Y}\right]-1\left(\partial \mathrm{S}^{*} / \partial \alpha 1\right)$,

$$
=\left[1-\partial \mathrm{S}^{*} / \partial \mathrm{Y}\right]-1\left(-\partial \mathrm{S}^{*} / \partial \mathrm{Y}\right) / \alpha_{2} \in\left(0,1 / \alpha_{2}\right),
$$

where $\partial S^{*} / \partial \alpha_{1}=-\left(\partial S^{*} / \partial Y\right) / \alpha_{2}$. Equation (17) shows that the marginal impact of the demand shifter $\alpha_{1}$ on the market equilibrium aggregate quantity $\mathrm{Y}^{\mathrm{e}}, \partial \mathrm{Y}^{\mathrm{e}} / \partial \alpha_{1}$, is positive and bounded between 0 and $\left(1 / \alpha_{2}\right)$. With $\mathrm{p}=\alpha_{1}-\alpha_{2} \mathrm{Y}$, this implies $\partial \mathrm{p}^{\mathrm{e}} / \partial \alpha_{1}=1-\alpha_{2}\left(\partial \mathrm{Y}^{\mathrm{e}} / \partial \alpha_{1}\right) \in(0,1)$. This is intuitive: any increase in demand (represented by a rise in $\left.\alpha_{1}\right)$ tends to increase the equilibrium price $\mathrm{p}^{\mathrm{e}}$. From (16), equation (17) also shows how $\partial \mathrm{Y}^{\mathrm{e}} / \partial \alpha_{1}$ depends on the structure of the industry (through $\mathrm{n}$ ) and on firms' conduct (through $\mathrm{v}$ ). In the absence of fixed cost, and when $\mathrm{n}$ is large and/or $\mathrm{c}_{2} / \alpha_{2}$ is 
small, we have seen that $\partial \mathrm{S}^{*} / \partial \mathrm{Y}<0$ tends to decrease with $\mathrm{n}$ (from Lemma 2). In this case, $\partial \mathrm{Y}^{\mathrm{e}} / \partial \alpha_{1}$ in (17) increases with $\mathrm{n}$. With $\mathrm{p}^{\mathrm{e}}=\alpha_{1}-\alpha_{2} \mathrm{Y}^{\mathrm{e}}$ where $\mathrm{p}^{\mathrm{e}}$ is the equilibrium price, it follows that $\partial \mathrm{p}^{\mathrm{e}} / \partial \alpha_{1}=1-\alpha_{2} \partial \mathrm{Y}^{\mathrm{e}} / \partial \alpha_{1}$ decreases with $\mathrm{n}$. These results are summarized next.

Proposition 5: In the absence of fixed cost $\left(\tilde{\mathrm{c}}_{0}=0\right)$,

a) $0<\partial \mathrm{p}^{\mathrm{e}} / \partial \alpha_{1} \leq 1$

b) when $\mathrm{n}$ is large and/or $\left(\mathrm{c}_{2} / \alpha_{2}\right)$ is small, then $\partial \mathrm{p}^{\mathrm{e}} / \partial \alpha_{1}$ tends to decrease with $\mathrm{n}$.

In the absence of fixed cost, result a) shows that the equilibrium price $\mathrm{p}^{\mathrm{e}}$ increases with an exogenous rise in demand (represented by an increase in $\alpha_{1}$ ). However, the supply response is such that the induced price increase tends to be less than the original shift in demand. Result b) shows that, if in addition $n$ is large and/or $c_{2} / \alpha_{2}$ is small, then the marginal price effect $\partial \mathrm{p}^{\mathrm{e}} / \partial \alpha_{1}$ decreases as the number $\mathrm{n}$ of active firms rises. Alternatively, as $\mathrm{n}$ declines, this price responsiveness would increase. This shows that the responsiveness of price adjustments to exogenous shocks is inversely related to the number of active firms in the market. Thus, a decreasing market concentration would contribute to reducing the price effect of a change in $\alpha_{1}$. Alternatively, thin or concentrated markets (where $n$ is low) would be characterized by greater price sensitivity to market changes. This discussion indicates that increasing (decreasing) market concentration would be associated with a higher (lower) price sensitivity to exogenous shocks.

\subsection{Case 3: The case of endogenous firms' conduct under fixed cost}

What happens if we introduce fixed costs in case 2? In the presence of fixed costs, the number of active firms $n(Y, v)$ depends in general on the firms' conduct v (from Proposition 3b). In this case, the determination of the equilibrium number of active firms becomes more complex. This illustrates the presence of important interactions between fixed costs, market structure, and industry behavior. To see that, given $n^{*}(v)$ in $(8 a)$ and $v^{*}(n)$ in $(12)$, let $g(n) \equiv n^{*}\left(v^{*}(n)\right)$. Then, the market equilibrium number $n^{e}$ of active firms must satisfy $n^{e}=g\left(n^{e}\right)$. Assuming that the market is large enough to support at least one active firm, (Note 13) a sufficient condition for the equation $n=g(n)$ to have a unique solution for $n$ is that $\partial \mathrm{g} / \partial \mathrm{n} \equiv\left(\partial \mathrm{n}^{*} / \partial \mathrm{v}\right)\left(\partial \mathrm{v}^{*} / \partial \mathrm{n}\right)<1$. The condition $\partial \mathrm{g} / \partial \mathrm{n}<1$ is always satisfied if $\partial \mathrm{v}^{*} / \partial \mathrm{n}=0$. This obviously holds in "case 1 " above. From Corollary $1 \mathrm{~b}$, the condition $\partial \mathrm{v}^{*} / \partial \mathrm{n}=0$ also holds under constant marginal cost $\left(\mathrm{c}_{2} \rightarrow 0\right)$ and $\mathrm{n}>2$. This indicates how assuming constant marginal cost can greatly facilitate the characterization of long run market equilibrium. (Note 14) Finally, given $\partial \mathrm{v}^{*} / \partial \mathrm{n} \in[-1,0]$ from Corollary $1 \mathrm{~b}$, the condition $\partial \mathrm{g} / \partial \mathrm{n}<1$ is satisfied if $\partial \mathrm{n}^{*} / \partial \mathrm{v}>$ -1 . Thus, in the presence of fixed costs, a sufficient condition to have a unique solution for the equilibrium number of firms ne is that $\partial \mathrm{n}^{*} / \partial \mathrm{v}>-1$. (Note 15)

Below, we assume that $\partial \mathrm{g} / \partial \mathrm{n}<1$. Then, applying the implicit function theorem to $\mathrm{n}=\mathrm{g}(\mathrm{n})$, we obtain the following properties of market equilibrium number ne of firms with respect to mean fixed cost $\overline{\mathrm{c}}_{0}$, mean variable cost $\overline{\mathrm{c}}_{1}$, and demand shifter $\alpha_{1}$.

Lemma 3: Assume that $\partial \mathrm{g} / \partial \mathrm{n}<1$. In the presence of fixed costs, the market equilibrium number ne of firms satisfies

$$
\partial \mathrm{n}^{\mathrm{e}} / \partial\left(\overline{\mathrm{c}}_{0}, \overline{\mathrm{c}}_{1}, \alpha_{1}\right)=[1-\partial \mathrm{g} / \partial \mathrm{n}]^{-1} \partial \mathrm{n}^{*} / \partial\left(\overline{\mathrm{c}}_{0}, \overline{\mathrm{c}}_{1}, \alpha_{1}\right),
$$

where

a) $\partial \mathrm{n}^{\mathrm{e}} / \partial \alpha_{1}=\operatorname{sign}\left\{\partial \mathrm{n}^{*} / \partial \alpha_{1}\right\}>0$,

b) $\partial \mathrm{n}^{\mathrm{e}} / \partial\left(\overline{\mathrm{c}}_{0}, \overline{\mathrm{c}}_{1}\right)=\operatorname{sign}\left\{\partial \mathrm{n} * / \partial\left(\overline{\mathrm{c}}_{0}, \overline{\mathrm{c}}_{1}\right)\right\}$.

Assuming $\partial \mathrm{g} / \partial \mathrm{n}<1$, equation (18) states that $\partial \mathrm{n}^{\mathrm{e}} / \partial\left(\overline{\mathrm{c}}_{0}, \overline{\mathrm{c}}_{1}, \alpha_{1}\right)$ is of the same as $\partial \mathrm{n}^{*} / \partial\left(\overline{\mathrm{c}}_{0}, \overline{\mathrm{c}}_{1}, \alpha_{1}\right)$. Noting that $\partial \mathrm{n}^{*} / \partial \alpha_{1}$ $\in\left(0,-[\partial \mathrm{n} / \partial \mathrm{Y}] / \alpha_{2}\right)$ (from Proposition 3d), this generates result a): $\partial \mathrm{n}^{\mathrm{e}} / \partial \alpha_{1}>0$. Thus, expanding demand (as represented by a rise in the parameter $\alpha_{1}$ ) has always a positive effect on the equilibrium number of active firms ne. Proposition $3 \mathrm{c}$ also showed that the effects of changing mean costs $\left(\bar{c}_{0}, \bar{c}_{1}\right)$ on $n^{*}$ can be either negative or positive (depending on whether the negative direct effects $\partial \mathrm{n} /\left(\overline{\mathrm{c}}_{0}, \overline{\mathrm{c}}_{1}\right)$ dominate the positive indirect effects $(\partial \mathrm{n} / \partial \mathrm{Y})\left(\partial \mathrm{Y}^{*} / \partial\left(\overline{\mathrm{c}}_{0}, \overline{\mathrm{c}}_{1}\right)\right)$ in $\left.(14)\right)$. From result b), similar results apply to the equilibrium number ne of firms. In our above discussion, we characterized as "normal" a situation where $\partial \mathrm{n}^{*} / \partial\left(\overline{\mathrm{c}}_{0}, \overline{\mathrm{c}}_{1}\right)<0$. It follows from $\mathrm{b}$ ) that increasing mean costs would tend to stimulate exit, $\partial \mathrm{n} / \partial\left(\overline{\mathrm{c}}_{0}, \overline{\mathrm{c}}_{1}\right)<0$, under a "normal situation". 
With ne denoting the equilibrium number of firms, the equilibrium aggregate quantity is then given by $\mathrm{Y}^{\mathrm{e}}=\mathrm{Y}^{*}\left(\mathrm{v}^{*}\left(\mathrm{n}^{\mathrm{e}}\right)\right)$. This gives

$$
\partial \mathrm{Y}^{\mathrm{e}} / \partial\left(\overline{\mathrm{c}}_{0}, \overline{\mathrm{c}}_{1}, \alpha_{1}\right)=\partial \mathrm{Y}^{*} / \partial\left(\overline{\mathrm{c}}_{0}, \overline{\mathrm{c}}_{1}, \alpha_{1}\right)+\left(\partial \mathrm{Y}^{*} / \partial \mathrm{v}\right)\left(\partial \mathrm{v}^{*} / \partial \mathrm{n}\right)\left(\partial \mathrm{n}^{\mathrm{e}} / \partial\left(\overline{\mathrm{c}}_{0}, \overline{\mathrm{c}}_{1}, \alpha_{1}\right)\right)
$$

Equation (19) evaluates the effects of mean fixed cost $\bar{c}_{0}$, mean variable cost $\bar{c}_{1}$, and the demand shifter $\alpha_{1}$ on the market equilibrium quantity $\mathrm{Y}^{\mathrm{e}}$. It decomposes the effects of $\left(\overline{\mathrm{c}}_{0}, \overline{\mathrm{c}}_{1}, \alpha_{1}\right)$ on $\mathrm{Y}^{\mathrm{e}}$ into two additive effects: the direct effects $\partial \mathrm{Y}^{*} / \partial\left(\overline{\mathrm{c}}_{0}, \overline{\mathrm{c}}_{1}, \alpha_{1}\right)$, which hold firm conduct $\mathrm{v}$ constant; and the indirect effects $\left(\partial \mathrm{Y}^{*} / \partial \mathrm{v}\right)\left(\partial \mathrm{v}^{*} / \partial \mathrm{n}\right)\left(\partial \mathrm{n}^{\mathrm{e}} / \partial\left(\overline{\mathrm{c}}_{0}, \overline{\mathrm{c}}_{1}\right.\right.$, $\left.\alpha_{1}\right)$ ), which capture the endogenous adjustments in firm conduct. The direct effects $\partial Y^{*} / \partial\left(\bar{c}_{0}, \bar{c}_{1}, \alpha_{1}\right)$ were evaluated in Lemma 1: $\partial \mathrm{Y}^{*} / \partial \alpha_{1} \in\left(0,1 / \alpha_{2}\right)$, and $\partial \mathrm{Y}^{*} / \partial\left(\overline{\mathrm{c}}_{0}, \overline{\mathrm{c}}_{1}\right)<0$. The indirect effects involve the interaction between three terms: $\partial \mathrm{Y}^{*} / \partial \mathrm{v}$ reflecting the response of aggregate supply to firm conduct; $\partial \mathrm{v}^{*} / \partial \mathrm{n}$ measuring the response of firm conduct to changing market structure; and $\partial \mathrm{n}^{\mathrm{e}} / \partial\left(\overline{\mathrm{c}}_{0}, \overline{\mathrm{c}}_{1}, \alpha_{1}\right)$ capturing the effects of $\left(\overline{\mathrm{c}}_{0}, \overline{\mathrm{c}}_{1}, \alpha_{1}\right)$ on net firm entry/exit. Each of these responses was analyzed above: $\partial \mathrm{Y}^{*} / \partial \mathrm{v}<0$ in Lemma $1 \mathrm{a} ; \partial \mathrm{v}^{*} / \partial \mathrm{n} \in[-1,0]$ in Corollary $1 \mathrm{~b}$; and $\partial \mathrm{n}^{\mathrm{e}} / \partial\left(\overline{\mathrm{c}}_{0}, \overline{\mathrm{c}}_{1}, \alpha_{1}\right)$ in Proposition 3 and Lemma 3. Since $\partial \mathrm{n}^{\mathrm{e}} / \partial \alpha_{1}>0$ from Lemma 3a, it follows that the indirect effect satisfies $\left(\partial \mathrm{Y}^{*} / \partial \mathrm{v}\right)$ $\left(\partial \mathrm{v}^{*} / \partial \mathrm{n}\right)\left(\partial \mathrm{n}^{\mathrm{e}} / \partial \alpha_{1}\right) \geq 0$, i.e. that the indirect effect of an increase in the demand shifter $\alpha_{1}$ on $\mathrm{Y}^{*}$ is always non-negative. However, while $\partial \mathrm{n}^{\mathrm{e}} / \partial\left(\overline{\mathrm{c}}_{0}, \overline{\mathrm{c}}_{1}\right)=\operatorname{sign}\left\{\partial \mathrm{n}^{*} / \partial\left(\overline{\mathrm{c}}_{0}, \overline{\mathrm{c}}_{1}\right)\right\}$ from Lemma $3 \mathrm{~b}$, we have seen that $\partial \mathrm{n}^{*} / \partial\left(\overline{\mathrm{c}}_{0}, \overline{\mathrm{c}}_{1}\right)$ can be either positive or negative (as analyzed in Proposition $3 \mathrm{c}$ ). These results are summarized next.

Proposition 6: Assume that $\partial \mathrm{g} / \partial \mathrm{n}<1$. In the presence of fixed costs, the market equilibrium aggregate quantity $\mathrm{Y}^{\mathrm{e}}$ satisfies

a) $\partial \mathrm{Y}^{\mathrm{e}} / \partial \alpha_{1} \geq \partial \mathrm{Y}^{*} / \partial \alpha_{1} \in\left(0,1 / \alpha_{2}\right)$,

b) $\partial \mathrm{Y}^{\mathrm{e}} / \partial\left(\overline{\mathrm{c}}_{0}, \overline{\mathrm{c}}_{1}\right)\left\{\begin{array}{l}< \\ = \\ >\end{array}\right\} \partial \mathrm{Y}^{*} / \partial\left(\overline{\mathrm{c}}_{0}, \overline{\mathrm{c}}_{1}\right)<0$, as $\partial \mathrm{n}^{*} / \partial\left(\overline{\mathrm{c}}_{0}, \overline{\mathrm{c}}_{1}\right)\left\{\begin{array}{l}< \\ >\end{array}\right\}$

Result a) gives the intuitive result that increasing demand always stimulates the equilibrium aggregate quantity: $\partial \mathrm{Y}^{\mathrm{e}} / \partial \alpha_{1}>0$. It also implies that $\partial \mathrm{Y}^{\mathrm{e}} / \partial \alpha_{1} \geq \partial \mathrm{Y}^{*} / \partial \alpha_{1}$ in general, and that $\partial \mathrm{Y}^{\mathrm{e}} / \partial \alpha_{1}>\partial \mathrm{Y}^{*} / \partial \alpha_{1}$ if the indirect effect of $\alpha_{1}$ is positive. This indicates that neglecting the role of entry/exit and firms' conduct tends to underestimate the effects of a demand shifter on aggregate quantity. Result b) shows the effects of changing mean fixed cost $\bar{c}_{0}$ and mean variable $\operatorname{cost} \overline{\mathrm{c}}_{1}$ on the market equilibrium quantity $\mathrm{Y}^{\mathrm{e}}$. It states that, in the presence of fixed cost, $\partial \mathrm{Y}^{\mathrm{e}} / \partial\left(\overline{\mathrm{c}}_{0}, \overline{\mathrm{c}}_{1}\right)<\partial \mathrm{Y}^{*} / \partial\left(\overline{\mathrm{c}}_{0}\right.$, $\left.\overline{\mathrm{c}}_{1}\right)<0$ when $\partial \mathrm{n}^{*} / \partial\left(\overline{\mathrm{c}}_{0}, \overline{\mathrm{c}}_{1}\right)<0$. Recall that we characterized as "normal" a situation where $\partial \mathrm{n}^{*} / \partial\left(\overline{\mathrm{c}}_{0}, \overline{\mathrm{c}}_{1}\right)<0$. Thus, in a "normal situation", we obtain the following two implications: increasing mean costs $\left(\bar{c}_{0}, \bar{c}_{1}\right)$ has a negative effect on aggregate quantity $\mathrm{Y}^{\mathrm{e}}$; and this effect is stronger than the direct effect $\partial \mathrm{Y}^{*} / \partial\left(\bar{c}_{0}, \bar{c}_{1}\right)$ in equation (19). (Note 16)

Proposition 6 can be used to evaluate the implications for pricing. Given $\mathrm{p}^{*}=\alpha_{1}-\alpha_{2} \mathrm{Y}^{*}$ and the market equilibrium price $\mathrm{p}^{\mathrm{e}}=\alpha_{1}-\alpha_{2} \mathrm{Y}^{\mathrm{e}}$, and following (19), we have

$$
\partial \mathrm{p}^{\mathrm{e}} / \partial\left(\overline{\mathrm{c}}_{0}, \overline{\mathrm{c}}_{1}, \alpha_{1}\right)=\partial \mathrm{p}^{*} / \partial\left(\overline{\mathrm{c}}_{0}, \overline{\mathrm{c}}_{1}, \alpha_{1}\right)+\left(\partial \mathrm{p}^{*} / \partial \mathrm{v}\right)\left(\partial \mathrm{v}^{*} / \partial \mathrm{n}\right)\left(\partial \mathrm{n}^{\mathrm{e}} / \partial\left(\overline{\mathrm{c}}_{0}, \overline{\mathrm{c}}_{1}, \alpha_{1}\right)\right) .
$$

This decomposes the marginal effects of $\left(\overline{\mathrm{c}}_{0}, \overline{\mathrm{c}}_{1}, \alpha_{1}\right)$ on market equilibrium price $\mathrm{p}, \partial \mathrm{p} / \partial\left(\overline{\mathrm{c}}_{0}, \overline{\mathrm{c}}_{1}, \alpha_{1}\right)$, into two additive parts: direct effects, $\partial \mathrm{p}^{*} / \partial\left(\overline{\mathrm{c}}_{0}, \overline{\mathrm{c}}_{1}, \alpha_{1}\right)$, holding firm conjecture $\mathrm{v}$ constant; and indirect effects, $\left(\partial \mathrm{p}^{*} / \partial \mathrm{v}\right)\left(\partial \mathrm{p}^{*} / \partial \mathrm{n}\right)$ $\left(\partial \mathrm{n}^{\mathrm{e}} / \partial\left(\overline{\mathrm{c}}_{0}, \overline{\mathrm{c}}_{1}, \alpha_{1}\right)\right)$, accounting for the endogenous adjustment in firm conduct. Again, note that the indirect effect involves interactions between firm conduct adjustments, $\partial \mathrm{v}^{*} / \partial \mathrm{n}$, and entry/exit effects, $\partial \mathrm{n}^{\mathrm{e}} / \partial\left(\overline{\mathrm{c}}_{0}, \overline{\mathrm{c}}_{1}, \alpha_{1}\right)$. The significance and importance of these interaction effects are further discussed below. Using Proposition 6 and equation (20), we obtain the following results.

Proposition 7: Assume that $\partial \mathrm{g} / \partial \mathrm{n}<1$. In the presence of fixed costs, the market equilibrium price $\mathrm{p}^{\mathrm{e}}$ satisfies 
a) $\partial \mathrm{p}^{\mathrm{e}} / \partial \alpha_{1} \leq \partial \mathrm{p}^{*} / \partial \alpha_{1} \in(0,1)$,

b) $\partial \mathrm{p}^{\mathrm{e}} / \partial\left(\overline{\mathrm{c}}_{0}, \overline{\mathrm{c}}_{1}\right)\left\{\begin{array}{l}> \\ = \\ <\end{array}\right\} \partial \mathrm{p}^{*} / \partial\left(\overline{\mathrm{c}}_{0}, \overline{\mathrm{c}}_{1}\right)>0$, as $\partial \mathrm{n}^{*} / \partial\left(\overline{\mathrm{c}}_{0}, \overline{\mathrm{c}}_{1}\right)\left\{\begin{array}{l}< \\ =\} \\ >\end{array}\right\}$.

Result a) states that the equilibrium price $\mathrm{p}^{\mathrm{e}}$ satisfies the following two properties: $\partial \mathrm{p}^{\mathrm{e}} / \partial \alpha_{1}<1$; and $\partial \mathrm{p}^{\mathrm{e}} / \partial \alpha_{1} \leq \partial \mathrm{p}^{*} / \partial \alpha_{1}$. The first property means that, due to the supply response, the induced price increase tends to be less than the original shift in demand. The second property shows that neglecting the role of entry/exit and firm conduct tends to overestimate the effects of a demand shifter on the equilibrium price $\mathrm{p}^{\mathrm{e}}$. This stresses the importance of properly accounting for changing industry structure in market analysis.

Result $b$ ) shows the effects of mean fixed cost $\bar{c}_{0}$ and mean variable cost $\bar{c}_{1}$ on market equilibrium price p $\mathrm{p}^{\mathrm{e}}$. It states that, in the presence of fixed cost, $\partial \mathrm{p}^{\mathrm{e}} / \partial\left(\overline{\mathrm{c}}_{0}, \overline{\mathrm{c}}_{1}\right)>\partial \mathrm{p}^{*} / \partial\left(\overline{\mathrm{c}}_{0}, \overline{\mathrm{c}}_{1}\right)>0$ when $\partial \mathrm{n}^{*} / \partial\left(\overline{\mathrm{c}}_{0}, \overline{\mathrm{c}}_{1}\right)<0$. In this case, the net effect of increasing cost $\left(\overline{\mathrm{c}}_{0}, \overline{\mathrm{c}}_{1}\right)$ on $\mathrm{p}^{\mathrm{e}}$ is stronger than the corresponding direct effect $\partial \mathrm{p}^{*} / \partial\left(\overline{\mathrm{c}}_{0}, \overline{\mathrm{c}}_{1}\right)$. Once more, this illustrates how neglecting the role of entry/exit and firm conduct can underestimate the effects of cost changes on the equilibrium price $\mathrm{p}^{\mathrm{e}}$. (Note 17)

The above results apply in the long run under entry/exit and fixed costs. How do they relate to previous literature? Below, we discuss scenarios where a simpler characterization of market equilibrium applies even in the presence of fixed costs. They involve the condition $\partial \mathrm{v}^{*} / \partial \mathrm{n}=0$. Note that $\partial \mathrm{v}^{*} / \partial \mathrm{n}=0$ means that $\mathrm{v}^{*}$ does not depend on $\mathrm{n}$ at least locally. This has an important implication: when $\partial \mathrm{v}^{*} / \partial \mathrm{n}=0$, then the analysis developed in "case 1 " above holds locally. It follows that under scenarios where $\partial \mathrm{v}^{*} / \partial \mathrm{n}=0$, all our market equilibrium results obtained under "case 1 " apply, with or without fixed costs. These scenarios are further discussed below.

In Corollary 1, we have investigated the determinants of $\mathrm{v}^{*}$ and $\partial \mathrm{v}^{*} / \partial \mathrm{n}$ in long run equilibrium. First, from Corollary 1 , we have shown that $\mathrm{v}^{*} \rightarrow 0$ (Cournot pricing) and $\partial \mathrm{v}^{*} / \partial \mathrm{n} \rightarrow 0$ when $\mathrm{n}$ is finite and $\mathrm{c}_{2} / \alpha_{2} \rightarrow \infty$. It follows that, under sharply increasing marginal cost $\left(c_{2} \rightarrow \infty\right)$ and/or a very elastic demand $\left(|\partial \mathrm{Y} / \partial \mathrm{p}|=1 / \alpha_{2} \rightarrow \infty\right)$, the effect of $n$ on $\mathrm{v}^{*}$ also vanishes: $\partial \mathrm{v}^{*} / \partial \mathrm{n} \rightarrow 0$. Under such circumstances, the market equilibrium is obtained by solving $\mathrm{Y}=\mathrm{S}(\mathrm{Y}, 0)$ for $\mathrm{Y}^{\mathrm{e}}$, with $\mathrm{n}^{\mathrm{e}}=\mathrm{n}^{*}(0)=\mathrm{n}\left(\mathrm{Y}^{\mathrm{e}}, 0\right)$. This result applies with or without fixed cost.

Second, Bertrand pricing is obtained from Corollary 1 when $\mathrm{n}$ is large. Indeed, from Corollary $1, \mathrm{n} \rightarrow \infty$ implies that $\mathrm{v}^{*} \rightarrow 1$ and $\partial \mathrm{v}^{*} / \partial \mathrm{n} \rightarrow 0$. This holds in the presence of fixed cost and for any finite $\mathrm{c}_{2} / \alpha_{2}$. This is the classical case where competitive behavior is obtained when the number of firms is sufficiently large. Under such circumstances, the market equilibrium quantity $\mathrm{Y}^{\mathrm{e}}$ is obtained by solving $\mathrm{Y}=\mathrm{S}(\mathrm{Y},-1)$, and the market equilibrium number of firms is $\mathrm{n}^{\mathrm{e}}=\mathrm{n}^{*}(-1)=$ $\mathrm{n}\left(\mathrm{Y}^{\mathrm{e}},-1\right)$ from $(8)$.

Third, from Corollary 1 , we have shown that $\mathrm{v}^{*}$ converges to Bertrand competition $(\mathrm{v} \rightarrow-1)$ and $\partial \mathrm{v}^{*} / \partial \mathrm{n} \rightarrow 0$ when $\mathrm{c}_{2} / \alpha_{2}$ $\rightarrow 0$ and $n>2$. It means that, when there are more than two active firms in the industry, and marginal cost is constant ( $c_{2}$ $\rightarrow 0)$ or demand is very inelastic $\left(|\partial \mathrm{Y} / \partial \mathrm{p}|=1 / \alpha_{2} \rightarrow 0\right)$, then the effect of $n$ on $v^{*}$ vanishes: $\partial \mathrm{v}^{*} / \partial \mathrm{n} \rightarrow 0$. Under such circumstances, market equilibrium is simple. Again, it is obtained by solving $\mathrm{Y}=\mathrm{S}(\mathrm{Y},-1)$, yielding $\mathrm{Y}^{\mathrm{e}}$ as the market equilibrium aggregate quantity. The associated equilibrium number of firms is $n^{e}=n^{*}(-1)=n\left(Y^{e},-1\right)$. This result applies with or without fixed costs. And with $n>2$, it does not require the number of firms to be large. This scenario represents a situation where Bertrand competition arises even if the number of firms is relatively small. By identifying an alternative way of generating competitive behavior, it provides useful insights on how globalization (leading to an increase in n) can lead an industry to behave more competitively in the long run.

\section{Implications for the economics of globalization}


Our analysis has investigated long run industry equilibrium allowing for both entry/exit and firm conduct. As noted in the introduction, the role of entry/exit has been stressed in previous literature (e.g., Melitz). One of our main contributions has been to add the role and determinants of firm conduct (or equivalently the role and determinants of markups charged by firms). This section explores the linkages with globalization issues. Globalization is typically associated with expanding market size and more active competition. For example, market liberalization policies can generate greater competition by allowing foreign firms to enter local markets and reducing the prevalence of local monopoly or oligopolies. In this case, globalization can generate benefit from reducing oligopoly rents. Such benefits would not be captured by models that assume constant markups (such as Melitz's model). Our analysis sheds new lights on this issue.

Intuitively, one expects firm entry in an industry to increase the number of active firms and intensify competitive behavior. We obtained such insights in Corollary 1, Lemma 2 and Proposition 5, where we explored the effects of market structure on firm conduct, supply response, and price adjustments, respectively. One problem with these arguments is that they take the number of active firms as exogenous. Our approach addresses this issue by endogenizing both entry/exit and firm conduct/markup, thus treating both as jointly determined parts of long run industry equilibrium. The properties of this equilibrium are summarized in Propositions 6 and 7. These propositions give information on two aspects of globalization: the effects of increasing market size (as measured by $\alpha_{1}$ ); and the effects of changing cost structures (as measured by $\overline{\mathrm{c}}_{0}, \overline{\mathrm{c}}_{1}$ ).

First, consider the effects of increasing market size $\alpha 1$. Propositions $6 \mathrm{a}$ and 7a give two important results. The first result is intuitive: increasing the size of the market (as measured by $\left.\alpha_{1}\right)$ tends to stimulate supply $\left(\partial \mathrm{Y}^{\mathrm{e}} / \partial \alpha_{1} \geq 0\right)$ and increase price $\left(\partial \mathrm{p}^{\mathrm{e}} / \partial \alpha_{1} \geq 0\right)$. The second result is of special significance here: allowing for adjustment in firm conduct/markups tends to strengthen the effects of market size: $\partial \mathrm{Y}^{\mathrm{e}} / \partial \alpha_{1} \geq \partial \mathrm{Y}^{*} / \partial \alpha_{1} \geq 0$, and $\partial \mathrm{p}^{\mathrm{e}} / \partial \alpha_{1} \geq \partial \mathrm{p}^{*} / \partial \alpha_{1} \geq 0$. In other words, treating firm conduct/markups as endogenous increases market equilibrium effects on aggregate quantity and price. These strengthening effects come from the indirect effects in equations (19) and (20). Importantly, these indirect effects involve interactions between entry/exit and adjustments in firm conduct. This is a key insight: these indirect effects would be zero if either industry structure is fixed or firm conduct is constant. In other words, the strengthening effects identified in Proposition $6 \mathrm{a}$ and $7 \mathrm{a}$ requires both entry/exit and adjustments in firm conduct. It means that previous models that neglected either entry/exit or adjustments in firm conduct would underestimate the aggregate effects of market size. Applied to trade, this indicates that previous models have frequently underestimated the gains from trade.

Second, consider the effects of changing cost structures. Propositions $6 \mathrm{~b}$ and $7 \mathrm{~b}$ present the long run equilibrium aggregate effects of changing mean fixed cost $\bar{c}_{0}$ and mean variable cost $\bar{c}_{1}$. As noted above, these effects are equivalent to cost changes that apply to all firms. But they are qualitatively similar to aggregate effects obtained from cost changes that apply to a subset of firms. Of course, the particular subset of firms affected by the change will have significant impact on the distribution of benefits. Yet, the impacts of changing cost structure on aggregate quantity and price would be qualitatively similar to the ones presented in Propositions $6 \mathrm{~b}$ and $7 \mathrm{~b}$. This means that Propositions $6 \mathrm{~b}$ and $7 \mathrm{~b}$ can be used to evaluate generic reductions in cost structure. The linkages with globalization become explicit when cost includes trade cost (which can be lowered by reducing transportation cost and/or reducing trade barriers through trade liberalization policies). In this context, Proposition $6 \mathrm{~b}$ and $7 \mathrm{~b}$ imply that, in a "normal situation" (where $\partial \mathrm{n}^{*} / \partial\left(\overline{\mathrm{c}}_{0}\right.$, $\left.\overline{\mathrm{c}}_{1}\right)<0$ ), allowing for adjustment in firm conduct/markups tends to strengthen the effects of globalization: $\partial \mathrm{Y}^{\mathrm{e}} / \partial\left(\overline{\mathrm{c}}_{0}, \overline{\mathrm{c}}_{1}\right)$ $\leq \partial \mathrm{Y}^{*} / \partial\left(\overline{\mathrm{c}}_{0}, \overline{\mathrm{c}}_{1}\right) \leq 0$, and $\partial \mathrm{p}^{\mathrm{e}} / \partial\left(\overline{\mathrm{c}}_{0}, \overline{\mathrm{c}}_{1}\right) \geq \partial \mathrm{p}^{*} / \partial\left(\overline{\mathrm{c}}_{0}, \overline{\mathrm{c}}_{1}\right) \geq 0$. This means that treating firm conduct/markups as endogenous increases market equilibrium effects on aggregate quantity and price. These strengthening effects come from the indirect effects in equations (19) and (20). Again, these indirect effects involve interactions between entry/exit 
and adjustments in firm conduct, and would be zero if either industry structure is fixed or firm conduct is constant. It means that previous models that neglected either entry/exit or adjustments in firm conduct would underestimate the aggregate effects of globalization. This stresses that a search for larger gains from globalization should include the joint determination of entry/exit and firm conduct/markups.

\section{Concluding remarks}

We have investigated firm behavior, pricing, and long run equilibrium for a single-product industry. The analysis allows for entry and exit of heterogeneous firms and applies irrespective of the firms' short-term strategies. It provides useful insights into the determinants of long run firms' conduct and equilibrium prices. In this context, we explored linkages between cost, equilibrium industry structure (number of active firms), with a special focus on the interactions between firms' conduct and entry/exit. Treating the number of active firms as endogenous, we showed how different cost structures can support alternative market structures (going from monopoly, to oligopoly, to competition), and alternative firms' conduct (including monopoly pricing, Cournot pricing, and Bertrand competition). We documented how Bertrand/competitive pricing can arise in the long run even when the number of active firms remains relatively small. We analyzed how the entry/exit process can influence the long-term evolution of both industry structure and the magnitude of supply adjustments to changing demand conditions. We also examined how supply responsiveness can vary with the cost structure of the industry.

Our analysis provides useful information on the economics of globalization. As a result of technological progress, reduced trade barriers, and the new information technology, markets have become more global. With global markets, the number of competing firms increases as markets become more integrated. Besides generating gains from trade, this affects firms' conduct and market behavior in the long run. We showed how globalization can help reduce the firms' exercise of market power, improve supply responsiveness, and reduce the price sensitivity to exogenous shocks. It also shows how neglecting either entry/exit or adjustments in firm conduct underestimates the aggregate effects of globalization. This stresses that a search for larger gains from globalization should include the joint determination of entry/exit and firm conduct/markups.

Our analysis has focused on long run industry equilibrium. It suggests some direction for future research. First, we analyzed the market for a homogeneous product. There is a need to explore further the relationships between structure and conduct for oligopolies producing differentiated products. Second, while our results apply irrespective of short-term firm strategies, further research can help shed light on how firms' conduct and industry behavior evolve toward their long run equilibrium. Since the associated dynamics are likely to vary across industries, this indicates a need for empirical investigations of linkages between cost, industry structure and firms' conduct.

\section{References}

Arkolakis, C., Demidova, S., Klenow P.J. \& Rodriguez-Clare A. (2008). Endogeneous Variety and the Gains from Trade. American Economic Review, 98, 444-450.

Baumol, W.J., Panzar, J.C. \& Willig, R.D. (1982). Contestable Markets and the Theory of Industry Structure. New York: Harcourt Brace Jovanovich, Inc.

Bresnahan, T.F. (1981). Duopoly Models with Consistent Conjectures. American Economic Review, 71, 934-945.

Dixit, A. (1984). International Trade Policy for Oligopolistic Industries. Economic Journal, 94, 1-16.

Dixit, A. (1986). Comparative Statics for Oligopoly. International Economic Review, 27, 107-122.

Dixon, H.D. \& Somma, E. (2003). The Evolution of Consistent Conjectures. Journal of Economic Behavior and Organization, 51, 523-536.

Dockner, E.J. (1992). A Dynamic Theory of Conjectural Variations. Journal of Industrial Economics, 40, $377-395$.

Ericson, R. \& Pakes, A. (1995). Markov-Perfect Industry Dynamics: A Framework for Empirical Work. Review of Economic Studies, 62, 53-82.

Feenstra, R.C. (2010). Measuring the Gains from Trade under Monopolistic Competition. Canadian Journal of Economics, 43, 1-28.

Friedman, D. (1991). Evolutionary Games in Economics. Econometrica, 59, 637-666. 
Friedman, J.W. \& Mezzetti, C. (2002). Bounded Rationality, Dynamic Oligopoly and Conjectural Variations. Journal of Economic Behavior and Organization, 49, 287-306.

Friedman, J.W. \& Thisse, J.F. (1994). Sustainable Collusion in Oligopoly with Free Entry. European Economic Review, $38,271-283$.

Genesove, D. \& Mullin, W.P. (1998). Testing Static Oligopoly Models: Conduct and Cost in the Sugar Industry, 1890-1914. Rand Journal of Economics, 29, 355-377.

Helpman, E. \& Krugman, P. (1989). Trade Policy and Market Structure. Cambridge: MIT Press.

Kamien, M.I. \& Schwartz, N.L. (1983). Conjectural Variations. Canadian Journal of Economics, 16, $191-211$.

Kreps, D. \& Scheinkman, J. (1983). Quantity Precommitment and Bertrand Competition Yield Cournot Outcomes. Bell Journal of Economics, 14, 326-337.

Lindh, T. (1992). The Inconsistency of Consistent Conjectures. Journal of Economic Behavior and Organization, 38 , 69-80.

MacLeod, W.B., Norman, G. \& Thisse J.F. (1987). Competition, Tacit Collusion and Free Entry. Economic Journal, 97, 189-198.

Makowsky, L. (1987). Are ‘Rational Conjectures’ Rational? Journal of Industrial Economics, 36, 35-37.

Melitz, M.J \& Ottaviano, G.I.P. (2008). Market Size, Trade and Productivity. Review of Economic Studies, 75, $295-316$.

Melitz, M.J. (2003). The Impact of Trade on Intra-Industry Reallocations and Aggregate Productivity. Econometrica, 71, $1695-1725$

Müeller, W. \& Normann, H.T. (2005). Conjectural Variations and Evolutionary Stability: A Rationale for Consistency. Journal of Institutional and Theoretical Economics, 161, 491-502.

Ortega, J.M. (1972). Numerical Analysis. New York: Academic Press.

Pavcnik, N. (2002). Trade Liberalization, Exit and Productivity Improvements: Evidence from Chilean Plants. Review of Economic Studies, 69, 245-276.

Perry, M.K. (1982). Oligopoly and Consistent Conjectural Variations. Bell Journal of Economics, 13, 197-205.

Scherer, F.M. (1980). Industrial Market Structure and Economic Performance. Boston: Houghton Mifflin Co.

Tanaka, Y. (1988). On Multiplicity of Consistent Conjectures in Free Entry Oligopoly. Economics Letters, 287, 109-115.

Tirole, J. (1988). The Theory of Industrial Organization. Cambridge: MIT Press.

Vega-Redondo, F. (1997). The Evolution of Walrasian Behavior. Econometrica, 65, 375-384.

\section{Notes}

Note 1. In a trade context, see Dixit (1984), and Helpman and Krugman.

Note 2. This follows Vega-Redondo and others. As shown by Friedman, there is a close relationship between stable dynamic steady state long run equilibrium and Nash equilibrium.

Note 3. This extends the analysis of duopoly presented by Dixon and Somma, and Mueller and Normann to general oligopolies under free entry.

Note 4. This implies that either $c_{2}>0$ or $v_{i}>-1$. It excludes the case where $c_{2}=0$ and $v_{i}=-1$. However, this case is not interesting in our analysis. Indeed, in the absence of fixed cost, this would yield an indeterminate firm size and number of firms. And in the presence of fixed cost, $c_{2}=0$ would imply a natural monopoly.

Note 5. The condition $\partial \mathrm{y}_{\mathrm{i}}^{+} / \partial \mathrm{Y}<0$ applies under the linear demand specification given in (1). Note that it may not apply under more general demand specifications. For example, it can fail to hold under a constant elasticity of demand. Importantly, the condition $\partial \mathrm{y}_{\mathrm{i}}^{+} / \partial \mathrm{Y}<0$ will be used in deriving our analytical results (e.g., it is used in the proof of Proposition 1). This indicates that considering more general demand specifications would compromise our ability to obtain analytical results. In other words, our focus on the linear demand specification given in (1) is motivated by our concern to preserve analytical tractability.

Note 6. Note that, in contrast with Tanaka, we allow for cost heterogeneity across firms. 
Note 7. This issue is examined in Lemma 1 below.

Note 8. Assuming that each firm chooses its own conduct independently of others rules out collusion. In the case of collusion, note that our analysis could still apply by treating the colluding firms as if they were a single firm. Given our focus on long run equilibrium, this would require the collusion to be sustained over an extended period of time. On this issue, see Friedman and Thisse, and MacLeod et al.

Note 9. In this context, the literature has defined "consistent conjectures" as conjectures satisfying $v_{i}=\partial x_{i}^{r}\left(y_{i}, v_{N}\right) / \partial y_{i}$, i.e. conjectures that are locally consistent with firms' interactions (e.g., Perry; Bresnahan; Dixit 1986). On the one hand, consistent conjectures have been criticized for lacking proper motivation from a game theory viewpoint (e.g., Lindh; Makowsky). On the other hand, they can be rationalized in a long run dynamic context (e.g., Dockner).

Note 10. This is consistent with Kreps and Scheinkman's finding that capacity constraints generate Cournot pricing.

Note 11. As shown by Perry, consistent conjectures generate Bertrand competition if marginal costs are constant.

Note 12. While $\partial \mathrm{n}^{*} / \partial\left(\overline{\mathrm{c}}_{0}, \overline{\mathrm{c}}_{1}\right)<0$ may be intuitive, it is not a general implication of our analysis. Indeed, our analysis is general enough to allow the indirect effect $(\partial \mathrm{n} / \partial \mathrm{Y})\left(\partial \mathrm{Y}^{*} / \partial\left(\overline{\mathrm{c}}_{0}, \overline{\mathrm{c}}_{1}\right)\right)$ to dominate in (14), implying $\partial \mathrm{n}^{*} / \partial\left(\overline{\mathrm{c}}_{0}, \overline{\mathrm{c}}_{1}\right)<0$. For example, this could occur when higher costs induce a large firm to exit, generating a large supply decline and a price increase that is large enough to induce the entry of several smaller firms.

Note 13. From equation $(8 \mathrm{~b})$, this means that we assume that $n\left(\mathrm{Y}^{*}(0), 0\right) \geq 1$.

Note 14. For example, Melitz's long run industry equilibrium analysis under monopolistic competition assumes constant marginal cost. Melitz's results would not hold without this assumption.

Note 15. Note that this sufficient condition is always satisfied in the absence of fixed cost, i.e. under "case 2 " above. Indeed, given $\partial \mathrm{n}^{*} / \partial \mathrm{v}=\partial \mathrm{n} / \partial \mathrm{v}+(\partial \mathrm{n} / \partial \mathrm{Y})\left(\partial \mathrm{Y}^{*} / \partial \mathrm{v}\right)$ from (14), the absence of fixed cost implies that $\partial \mathrm{n} / \partial \mathrm{v}=0$ (from Proposition $3 \mathrm{~b}$ ), $\partial \mathrm{n} / \partial \mathrm{Y}<0$ (from Proposition 3a) and $\partial \mathrm{Y}^{*} / \partial \mathrm{v}<0$ (from Lemma 1a), yielding $\partial \mathrm{n}^{*} / \partial \mathrm{v}>0>-1$. However, in the presence of fixed cost, $\partial \mathrm{n} / \partial \mathrm{v}<0$ from (B10b), and equation (14) implies that it becomes possible to have $\partial \mathrm{n}^{*} / \partial \mathrm{v}<$ -1. In this case, $n^{e}=g\left(n^{e}\right)$ could exhibit multiple equilibrium.

Note 16. However, this latter finding does not hold when $\partial \mathrm{n}^{*} / \partial\left(\overline{\mathrm{c}}_{0}, \overline{\mathrm{c}}_{1}\right)>0$. Then, $\partial \mathrm{Y}^{\mathrm{e}} / \partial\left(\overline{\mathrm{c}}_{0}, \overline{\mathrm{c}}_{1}\right)>\partial \mathrm{Y}^{*} / \partial\left(\overline{\mathrm{c}}_{0}, \overline{\mathrm{c}}_{1}\right)<0$. In this case, note that it is even possible for $\partial \mathrm{Y}^{\mathrm{e}} / \partial\left(\overline{\mathrm{c}}_{0}, \overline{\mathrm{c}}_{1}\right)$ to be positive. This could occur when the indirect effect in (19), $\left(\partial \mathrm{Y}^{*} / \partial \mathrm{v}\right)\left(\partial \mathrm{v}^{*} / \partial \mathrm{n}\right)\left(\partial \mathrm{n}^{\mathrm{e}} / \partial\left(\overline{\mathrm{c}}_{0}, \overline{\mathrm{c}}_{1}\right)\right)$, is positive and large enough to dominate the direct effect, $\partial \mathrm{Y}^{*} / \partial\left(\overline{\mathrm{c}}_{0}, \overline{\mathrm{c}}_{1}\right)$.

Note 17. Again, this finding does not hold when $\partial \mathrm{n}^{*} / \partial\left(\overline{\mathrm{c}}_{0}, \overline{\mathrm{c}}_{1}\right)>0$. Then, the net effect of $\left(\overline{\mathrm{c}}_{0}, \overline{\mathrm{c}}_{1}\right)$ on price becomes less positive (compared to the positive direct effect) as $\partial \mathrm{p}^{\mathrm{e}} / \partial\left(\overline{\mathrm{c}}_{0}, \overline{\mathrm{c}}_{1}\right)<\partial \mathrm{p}^{*} / \partial\left(\overline{\mathrm{c}}_{0}, \overline{\mathrm{c}}_{1}\right)>0$. 


\section{Appendix}

Proof of Proposition 1: The proof consists in showing that the solution to (11b) is a contaction mapping. We present the proof letting $\varepsilon=1$ in (11a)-(11b). For simplicity, we drop the time superscript " $t$ ". Using $\pi_{i}\left(y_{i}, x_{i}\right)=p\left(y_{i}+x_{i}\right) y_{i}-$ $\mathrm{C}_{\mathrm{i}}\left(\mathrm{y}_{\mathrm{i}}\right)$, the first-order necessary conditions for an interior solution to $(11 \mathrm{~b})$ are

$\left[\partial \pi_{\mathrm{i}}\left(\mathrm{y}_{\mathrm{i}}, \mathrm{x}_{\mathrm{i}}\right) / \partial \mathrm{y}_{\mathrm{i}}+\left(\partial \pi_{\mathrm{i}}\left(\mathrm{y}_{\mathrm{i}}, \mathrm{x}_{\mathrm{i}}\right) / \partial \mathrm{x}_{\mathrm{i}}\right)\left(\partial \mathrm{x}_{\mathrm{i}}^{\mathrm{r}}\left(\mathrm{y}_{\mathrm{i}}, \mathbf{v}_{\mathrm{N}-\mathrm{i}}\right) / \partial \mathrm{y}_{\mathrm{i}}\right)\right]\left(\partial \mathrm{y}_{\mathrm{i}}^{*}\left(\mathbf{v}_{\mathrm{N}}\right) / \partial \mathrm{v}_{\mathrm{i}}\right)=0$,

$\mathrm{i} \in \mathrm{N}$. Equation (4a) can be written as $\partial \pi_{\mathrm{i}}\left(\mathrm{y}_{\mathrm{i}}, \mathrm{x}_{\mathrm{i}}\right) / \partial \mathrm{y}_{\mathrm{i}}=-\mathrm{v}_{\mathrm{i}} \quad \partial \pi_{\mathrm{i}}\left(\mathrm{y}_{\mathrm{i}}, \mathrm{x}_{\mathrm{i}}\right) / \partial \mathrm{x}_{\mathrm{i}}, \mathrm{i} \in \mathrm{N}$. Substituting into (B1) yields

$\mathrm{Q}_{\mathrm{i}} \equiv\left(\partial \pi_{\mathrm{i}}\left(\mathrm{y}_{\mathrm{i}}, \mathrm{x}_{\mathrm{i}}\right) / \partial \mathrm{x}_{\mathrm{i}}\right)\left[-\mathrm{v}_{\mathrm{i}}+\partial \mathrm{x}_{\mathrm{i}}^{\mathrm{r}}\left(\mathrm{y}_{\mathrm{i}}, \mathbf{v}_{\mathrm{N}-\mathrm{i}}\right) / \partial \mathrm{y}_{\mathrm{i}}\right]\left(\partial \mathrm{y}_{\mathrm{i}}^{*}\left(\mathbf{v}_{\mathrm{N}}\right) / \partial \mathrm{v}_{\mathrm{i}}\right)=0$,

$\mathrm{i} \in \mathrm{N}$. Note that $\partial \pi_{\mathrm{i}}\left(\mathrm{y}_{\mathrm{i}}, \mathrm{x}_{\mathrm{i}}\right) / \partial \mathrm{x}_{\mathrm{i}}=-\alpha_{2} \mathrm{y}_{\mathrm{i}}^{*}<0$ when the $\mathrm{i}$-th firm is active. Differentiating equation (7) yields $\partial \mathrm{y}_{\mathrm{i}}^{*} / \partial \mathrm{v}_{\mathrm{i}}=$ $\partial \mathrm{y}_{\mathrm{i}}^{+} / \partial \mathrm{v}_{\mathrm{i}}+\left(\partial \mathrm{y}_{\mathrm{i}}^{+} / \partial \mathrm{Y}\right)\left(\partial \mathrm{Y}^{*} / \partial \mathrm{v}_{\mathrm{i}}\right)$. Under the specification (1)-(2), note that $\partial \mathrm{y}_{\mathrm{i}}^{+} / \partial \mathrm{v}_{\mathrm{i}}<0, \partial \mathrm{y}_{\mathrm{i}}^{+} / \partial \mathrm{Y}<0$ and $\partial \mathrm{Y}^{*} / \partial \mathrm{v}_{\mathrm{i}} \leq 0$ (from equations (6a)-(6b)). It follows that $\partial \mathrm{y}_{\mathrm{i}}{ }^{*} / \partial \mathrm{v}_{\mathrm{i}}<0$. This implies from (B2) that the solution of (11b) for the conduct of the i-th firm must satisfy

$\mathrm{v}_{\mathrm{i}}^{+}=\partial \mathrm{x}_{\mathrm{i}}^{\mathrm{r}}\left(\mathrm{y}_{\mathrm{i}}, \mathbf{v}_{\mathrm{N}-\mathrm{i}}\right) / \partial \mathrm{y}_{\mathrm{i}}, \mathrm{i} \in \mathrm{N}$.

Under the specification (1)-(2), applying the implicit function theorem to equation (10) gives $\partial \mathrm{x}_{\mathrm{i}}^{\mathrm{r}}\left(\mathrm{y}_{\mathrm{i}}, \mathbf{v}_{\mathrm{N}-\mathrm{i}}\right) / \partial \mathrm{y}_{\mathrm{i}}=$ $\sum_{j \neq i}\left(I_{j} \cdot \frac{-a_{2}}{c_{2}+\alpha_{2}\left(1+v_{j}\right)}\right) /\left[1+\sum_{j \neq i}\left(I_{j} \cdot \frac{a_{2}}{c_{2}+\alpha_{2}\left(1+v_{j}\right)}\right)\right] \cdot$

It follows from $(\mathrm{B} 3)$ that $\mathrm{v}_{\mathrm{i}}{ }^{*} \in(-1,0), \mathrm{i} \in \mathrm{N}$, i.e. that the solution for the $\mathrm{v}_{\mathrm{i}}$ 's is interior. The second order condition for a maximum in (11) is satisfied: $\partial \mathrm{Q}_{\mathrm{i}} / \partial \mathrm{v}_{\mathrm{i}}<0$. The first-order condition (B2) can then be written as

$$
\mathrm{v}_{\mathrm{i}}^{+}=\mathrm{h}_{\mathrm{i}}\left(\mathbf{v}_{\mathrm{N}-\mathrm{i}}, \mathrm{N}\right) \equiv \sum_{\mathrm{j} \neq \mathrm{i}}\left(\mathrm{I}_{\mathrm{j}} \cdot \frac{-\alpha_{2}}{\mathrm{c}_{2}+\alpha_{2}\left(1+\mathrm{v}_{\mathrm{j}}\right)}\right) /\left[1+\sum_{\mathrm{j} \neq \mathrm{i}}\left(\mathrm{I}_{\mathrm{j}} \cdot \frac{\alpha_{2}}{\mathrm{c}_{2}+\alpha_{2}\left(1+\mathrm{v}_{\mathrm{j}}\right)}\right)\right], \mathrm{i} \in \mathrm{N},
$$

(B4)

This is a system of equations with $\mathrm{v}_{\mathrm{N}}=\left\{\mathrm{v}_{\mathrm{i}}: \mathrm{i} \in \mathrm{N}\right\}$ as unknowns. Differentiating the right-hand side of (B4) with respect to $\mathrm{v}_{\mathrm{k}}$ yields, for $\mathrm{k} \in \mathrm{N}, \mathrm{k} \neq \mathrm{i}$,

$$
\frac{\partial \mathrm{h}_{\mathrm{i}}\left(\mathbf{v}_{\mathrm{N}-\mathrm{i}}, \mathrm{N}\right)}{\partial \mathrm{v}_{\mathrm{k}}}=\mathrm{I}_{\mathrm{k}}\left(\frac{\alpha_{2}}{\mathrm{c}_{2}+\alpha_{2}\left(1+\mathrm{v}_{\mathrm{k}}\right)}\right)^{2}\left(\frac{1}{1+\sum_{\mathrm{j} \neq \mathrm{i}}\left(\mathrm{I}_{\mathrm{j}} \cdot \frac{\alpha_{2}}{\mathrm{c}_{2}+\alpha_{2}\left(1+\mathrm{v}_{\mathrm{j}}\right)}\right)}\right)^{2} \text {. }
$$

Noting that $\sum_{\mathrm{k} \neq \mathrm{i}}\left(\mathrm{I}_{\mathrm{k}} \cdot \frac{\alpha_{2}}{\mathrm{c}_{2}+\alpha_{2}\left(1+\mathrm{v}_{\mathrm{k}}\right)}\right)^{2}<\left(1+\sum_{\mathrm{j} \neq \mathrm{i}}\left(\mathrm{I}_{\mathrm{j}} \cdot \frac{\alpha_{2}}{\mathrm{c}_{2}+\alpha_{2}\left(1+\mathrm{v}_{\mathrm{j}}\right)}\right)\right)^{2}$ and that $\frac{\partial \mathrm{h}_{\mathrm{i}}\left(\mathrm{v}_{\mathrm{N}-\mathrm{i}}, \mathrm{N}\right)}{\partial \mathrm{v}_{\mathrm{i}}}=0$, it follows that

$$
\sum_{\mathrm{k} \in \mathrm{N}}\left(\frac{\partial \mathrm{h}_{\mathrm{i}}\left(\mathbf{v}_{\mathrm{Ni}} \mathrm{i}\right)}{\partial \mathrm{v}_{\mathrm{k}}}\right)<1, \mathrm{i} \in \mathrm{N}
$$

Condition (B5) implies that the system of equations (B4) is a contraction mapping in $\mathrm{v}_{\mathrm{N}}$ (Ortegas, p. 154). From the contraction-mapping theorem, it follows that equation (B4) has a unique solution $\mathrm{v}_{\mathrm{N}}{ }^{*}$. To find the solution, consider the case where the $v_{i}$ 's are constant across active firms: $v_{i}=v$ for $i \in N$. Then (B4) becomes $v=-(n-1) /\left(v+n+c_{2} / \alpha_{2}\right)$. This generates the quadratic equation: $\mathrm{v}^{2}+\left(\mathrm{n}+\mathrm{c}_{2} / \alpha_{2}\right) \mathrm{v}+(\mathrm{n}-1)=0$, which has for solutions $\mathrm{v}^{*}=-1 / 2\left(\mathrm{n}+\mathrm{c}_{2} / \alpha_{2}\right) \pm 1 / 2 \sqrt{\left(\mathrm{n}+\mathrm{c}_{2} / \alpha_{2}\right)^{2}-4(\mathrm{n}-1)}$.

But only the positive root satisfies $v^{*} \geq-1$. Thus, the unique long run equilibrium conduct is given by equation (12).

Proof of Lemma 1: The joint distribution function for $\left(\mathrm{c}_{0 \mathrm{i}}, \mathrm{c}_{\mathrm{li}}\right)$ across all $\mathrm{m}$ firms is $\mathrm{F}\left(\tilde{\mathrm{c}}_{0}, \tilde{\mathrm{c}}_{1}\right)$, where $\mathrm{F}(\mathrm{a}, \mathrm{b})=$

$$
\int_{\tilde{c}_{0} \leq a} \int_{\tilde{c}_{1} \leq b} \mathrm{f}\left(\tilde{\mathrm{c}}_{0}, \tilde{\mathrm{c}}_{1}\right) \mathrm{d} \tilde{\mathrm{c}}_{1} \mathrm{~d} \tilde{\mathrm{c}}_{0}, \mathrm{f}\left(\tilde{\mathrm{c}}_{0}, \tilde{\mathrm{c}}_{1}\right) \text { being the joint probability density function of }\left(\tilde{\mathrm{c}}_{0}, \tilde{\mathrm{c}}_{1}\right) \text {. Given } \mathrm{v}_{\mathrm{i}}=\mathrm{v} \text { for active firms }
$$


and from (6b), aggregate production is given by

$$
\mathrm{S}(\mathrm{Y}, \mathrm{v}) \equiv \mathrm{m} \int_{\tilde{\mathrm{c}}_{0}} \int_{\tilde{\mathrm{c}}_{1} \leq \mathrm{K}(\cdot)}\left[\alpha_{1}-\alpha_{2} \mathrm{Y}-\tilde{\mathrm{c}}_{1}\right] /\left[\mathrm{c}_{2}+\alpha_{2}(1+\mathrm{v})\right] \mathrm{dF}\left(\tilde{\mathrm{c}}_{0}, \tilde{\mathrm{c}}_{1}\right),
$$

where $\tilde{\mathrm{c}}_{1} \leq \mathrm{K}(\cdot)$ denotes the non-negative profit constraints $\left\{\tilde{\mathrm{c}}_{1} \leq \mathrm{K}\left(\mathrm{Y}, \tilde{\mathrm{c}}_{0}, \mathrm{v}\right)\right\}$, with $\mathrm{K}\left(\mathrm{Y}, \tilde{\mathrm{c}}_{0}, \mathrm{v}\right) \equiv \alpha_{1}-\alpha_{2} \mathrm{Y}-$ $\sqrt{\tilde{\mathrm{c}}_{0}} \frac{\mathrm{c}_{2}+\alpha_{2}(1+\mathrm{v})}{\sqrt{? \mathrm{c}_{2}+\alpha_{2}(1+\mathrm{v})}}$. In addition, from $(8 \mathrm{~b})$, the number of active firms is

$$
\mathrm{n}(\mathrm{Y}, \mathrm{v})=\mathrm{m} \int_{\tilde{\mathrm{c}}_{0}} \int_{\tilde{\tilde{c}}_{1} \leq \mathrm{K}(\cdot)} \mathrm{dF}\left(\tilde{\mathrm{c}}_{0}, \tilde{\mathrm{c}}_{1}\right)
$$

with $\mathrm{n}(\mathrm{Y}, \mathrm{v}) \leq \mathrm{m}$. Using Leibniz's rule, differentiating $\mathrm{S}(\cdot)$ in $(\mathrm{B} 6)$ gives

$$
\partial \mathrm{S} / \partial \mathrm{Y}=-\alpha_{2}\left[\frac{\mathrm{n}}{\mathrm{c}_{2}+\alpha_{2}(1+\mathrm{v})}+\frac{\mathrm{m}}{\sqrt{1 / 2 \mathrm{c}_{2}+\alpha_{2}(1+\mathrm{v})}} \int_{\tilde{\mathrm{c}}_{0}} \sqrt{\tilde{\mathrm{c}}_{0}} \mathrm{f}\left(\tilde{\mathrm{c}}_{0}, \mathrm{~K}(\cdot)\right) \mathrm{d} \tilde{\mathrm{c}}_{0}\right]<0,
$$

using (B7),

$$
\begin{aligned}
\partial \mathrm{S} / \partial \mathrm{v} & =-\frac{\alpha_{2} \mathrm{~S}}{\mathrm{c}_{2}+\alpha_{2}(1+\mathrm{v})}+\mathrm{m} \int_{\widetilde{\mathrm{c}}_{0}} \frac{\sqrt{\widetilde{\mathrm{c}}_{0}}}{\sqrt{1 / 2 \mathrm{c}_{2}+\alpha_{2}(1+\mathrm{v})}} \mathrm{f}\left(\tilde{\mathrm{c}}_{0}, \mathrm{~K}(\cdot)\right)(\partial \mathrm{K} / \partial \mathrm{v}) \mathrm{d} \tilde{\mathrm{c}}_{0}, \\
& =-\frac{\alpha_{2} \mathrm{~S}}{\mathrm{c}_{2}+\alpha_{2}(1+\mathrm{v})}-\frac{\mathrm{m} \alpha_{2}^{2}(1+\mathrm{v})}{2\left[\mathrm{c}_{2}+\alpha_{2}(1+\mathrm{v})\right]^{2}} \int_{\tilde{\mathrm{c}}_{0}} \tilde{\mathrm{c}}_{0} \mathrm{f}\left(\tilde{\mathrm{c}}_{0}, \mathrm{~K}(\cdot)\right) \mathrm{d} \tilde{\mathrm{c}}_{0}<0,
\end{aligned}
$$

since $\partial \mathrm{K} / \partial \mathrm{v}=-\sqrt{\widetilde{\mathrm{c}}_{0}} \frac{\alpha_{2}^{2}(1+\mathrm{v})}{2\left[\mathrm{c}_{2}+\alpha_{2}(1+\mathrm{v})\right]^{3 / 2}}$,

$$
\begin{aligned}
& \partial \mathrm{S} / \partial \overline{\mathrm{c}}_{0}=-\frac{1 / 2 \mathrm{~m}\left[\mathrm{c}_{2}+\alpha_{2}(1+\mathrm{v})\right]}{1 / 2 \mathrm{c}_{2}+\alpha_{2}(1+\mathrm{v})} \int_{\tilde{\mathrm{c}}_{0}} \mathrm{f}\left(\tilde{\mathrm{c}}_{0}, \mathrm{~K}(\cdot)\right) \mathrm{d} \tilde{\mathrm{c}}_{0}<0, \\
& \partial \mathrm{S} / \partial \overline{\mathrm{c}}_{1}=(\partial \mathrm{S} / \partial \mathrm{Y}) / \alpha_{2}=-\frac{\mathrm{n}}{\mathrm{c}_{2}+\alpha_{2}(1+\mathrm{v})}-\frac{\mathrm{m}}{\sqrt{1 / 2 \mathrm{c}_{2}+\alpha_{2}(1+\mathrm{v})}} \int_{\tilde{\mathrm{c}}_{0}} \sqrt{\tilde{\mathrm{c}}_{0}} \mathrm{f}\left(\tilde{\mathrm{c}}_{0}, \mathrm{~K}(\cdot)\right) \mathrm{d} \tilde{\mathrm{c}}_{0},<0,
\end{aligned}
$$

and

$$
\partial \mathrm{S} / \partial \alpha_{1}=-(\partial \mathrm{S} / \partial \mathrm{Y}) / \alpha_{2}<0
$$

(B8e)

Note that the right-hand side of equations (B8a) and (B8b) involve two additive terms. The first term is associated with production adjustments by incumbent firms. The second term is associated with the entry/exit process of marginal firms. This term vanishes in the absence of fixed cost (where $c_{0 \mathrm{i}}=0$ ), illustrating the importance of fixed cost in the entry/exit process.

With $\mathrm{Y}^{*}$ solving $\mathrm{Y}=\mathrm{S}(\mathrm{Y}, \mathrm{v})$, applying the implicit function theorem and using (B8) yield

$$
\begin{aligned}
& \partial \mathrm{Y}^{*} / \partial\left(\mathrm{v}, \overline{\mathrm{c}}_{0}, \overline{\mathrm{c}}_{1}\right)=[1-\partial \mathrm{S} / \partial \mathrm{Y}]^{-1} \partial \mathrm{S} / \partial\left(\mathrm{v}, \overline{\mathrm{c}}_{0}, \overline{\mathrm{c}}_{1}\right)<0, \\
& \partial \mathrm{Y}^{*} / \partial \alpha_{1}=-[1-\partial \mathrm{S} / \partial \mathrm{Y}]^{-1}(\partial \mathrm{S} / \partial \mathrm{Y}) / \alpha_{2} \in\left(0,1 / \alpha_{2}\right) .
\end{aligned}
$$

Proof of Proposition 3: The number of active firms $n(Y, v)$ is given in (B7). Using Leibniz's rule, differentiating $n(\cdot)$ in (B7) gives

$$
\begin{aligned}
& \partial \mathrm{n} / \partial \mathrm{Y}=-\mathrm{m} \int_{\widetilde{q}} \alpha_{2} \mathrm{f}\left(\widetilde{\mathrm{c}}_{0}, \mathrm{~K}(\cdot)\right) \mathrm{d} \widetilde{\mathrm{c}}_{0}<0, \\
& \partial \mathrm{n} / \partial \mathrm{v}=\mathrm{m} \int_{\widetilde{\mathrm{q}}_{0}} \mathrm{f}\left(\widetilde{\mathrm{c}}_{0}, \mathrm{~K}(\cdot)\right)(\partial \mathrm{K} / \partial \mathrm{v}) \mathrm{d} \widetilde{\mathrm{c}}_{0},
\end{aligned}
$$




$$
\begin{aligned}
& =-\frac{\mathrm{m} \alpha_{2}^{2}(1+\mathrm{v})}{2\left[\mathrm{c}_{2}+\alpha_{2}(1+\mathrm{v})\right]^{3 / 2}} \int_{\widetilde{\mathrm{q}}_{\mathrm{o}}} \sqrt{\tilde{\mathrm{c}}_{0}} \mathrm{f}\left(\tilde{\mathrm{c}}_{0}, \mathrm{~K}(\cdot)\right) \mathrm{d} \tilde{\mathrm{c}}_{0} \leq 0, \\
\partial \mathrm{n} / \partial \overline{\mathrm{c}}_{0} & =\mathrm{m} \frac{\partial}{\partial \overline{\mathrm{c}}_{0}}\left[\int_{\tilde{\mathrm{q}}_{0} \leq K} \int_{\tilde{\mathrm{c}}_{1} \leq \mathrm{f}} \mathrm{f}\left(\tilde{\mathrm{c}}_{0}, \tilde{\mathrm{c}}_{1}\right) \mathrm{d} \tilde{\mathrm{c}}_{0} \mathrm{~d} \tilde{\mathrm{c}}_{1}\right]<0,
\end{aligned}
$$

since $\mathrm{K}(\cdot)$ is strictly decreasing in $\tilde{\mathrm{c}}_{0} \geq 0$,

$$
\begin{aligned}
& \partial \mathrm{n} / \partial \bar{c}_{1}=(\partial \mathrm{n} / \partial \mathrm{Y}) / \alpha_{2}<0 \\
& \partial \mathrm{n} / \partial \alpha_{1}=-(\partial \mathrm{n} / \partial \mathrm{Y}) / \alpha_{2}>0
\end{aligned}
$$

Result b) then follows from equation (14), using Lemma 1 along with equations (B10c) and (B10d). And result c) is obtained from equations (14), (B10a), (B10e) and Lemma 1. In addition, note that equations (14) and (B10e) give $\partial \mathrm{n}^{*} / \partial \alpha_{1}=\partial \mathrm{n} / \partial \alpha_{1}+(\partial \mathrm{n} / \partial \mathrm{Y})\left(\partial \mathrm{Y}^{*} / \partial \alpha_{1}\right)=(\partial \mathrm{n} / \partial \mathrm{Y})\left[-1 / \alpha_{2}+\partial \mathrm{Y}^{*} / \partial \alpha_{1}\right]>0$ since $\partial \mathrm{n} / \partial \mathrm{Y}<0$ from $(\mathrm{B} 10 \mathrm{a})$ and $\partial \mathrm{Y}^{*} / \partial \alpha_{1} \in\left(0,1 / \alpha_{2}\right)$ from Lemma $1 \mathrm{~d}$.



Figure 1. Firm conduct $v^{*}(n)$ as a function of the number $n$ of active firms, for selected values of the parameter $k \equiv c_{2} / \alpha_{2}$. 